\title{
DOE/PC/92119--T7
}

Contract No. DEAC2292PC92119

\section{Microbial Recovery of Metals from Spent Coal Liquefaction Catalysts}

\author{
Final \\ and \\ Quarterly Report
}

Quarterly Report, July - September, 1994

DISCLAIMER

This report was prepared as an account of work sponsored by an agency of the United States Government. Neither the United States Government nor any agency thereof, nor any of their employees, makes any warranty, express or implied, or assumes any legal liability or responsibility for the accuracy, completeness, or usefulness of any information, apparatus, product, or process disclosed, or represents that its use would not infringe privately owned rights. Reference herein to any specific commercial product, process, or service by trade name, trademark, manufacturer, or otherwise does not necessarily constitute or imply its endorsement, recommendation, or favoring by the United States Government or any agency thereof. The views and opinions of authors expressed herein do not necessarily state or reflect those of the United States Government or any agency thereof.

Dr. Kennth A. Sandbeck, Principal Investigator and

Dale Cleveland

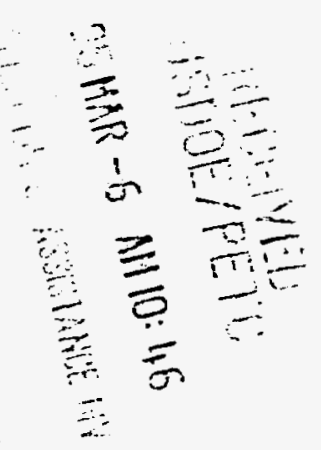

\section{Geo-Microbial Technologies, Inc. East Main Street \\ P.O. Box 132 \\ Ochelata, Oklahoma 74051}

QLEARED BY

PATENT COUNSEL

DISTRIBUTION OF THIS DOCUMENT IS UNLMMTED

Yar 


\section{DISCLAIMER}

Portions of this document may be illegible in electronic image products. Images are produced from the best available original document. 


\section{Summary}

Mo release from spent coal liquefaction catalysts has been shown to be dependent upon many parameters, but release is dominated by microbial growth. The microbial Mo release is a rapid process requiring less than one week for $90 \%$ of the releaseable Mo to be solubilized from whole washed (THF) catalyst. It could be expected that the rates would be even greater with crushed catalyst. Efforts were centered on optimizing the parameters that stimulate microbial growth and action and further efforts centered on catalyst pre-treatment prior to microbial bio-leaching. Recent experiments suggest that hydrogen peroxide promises to be an effective pretreatment wash. Hydrogen peroxide was also found to be an effective and economical agent for metals solubilization per se and could promote solubilization without subjecting the catalyst to microbial growth.

\section{Project Objective}

The project objectives outlined in the previous reports involved defining conditions and cultures best suited to achieve the most effective metal release from spent coal liquefaction catalysts by microbial processes. Various microbiological and physiochemical parameters which may be important in microbial release of metals from spent coal liquefaction catalysts were investigated so that this technology could be optimized.

\section{Introduction}

The work initiated in the first and second quarters of 1994 was continued and expanded using solvent extraction systems defined by the multiple solvent tests used for washing the catalysts. Several of the solvents had desirable characteristics and would provide an extracted test catalyst which would respond well to the leaching ability of the cultures. Upon review of the data, tetrahydrofuran (THF) was selected as a representative system following consideration of attributes including cost, ease of handling, and extractive capabilities. In the present simplified, extractive system, the catalysts are washed with the solvent with simple agitation to prevent catalyst breakage. This approach of using unbroken catalyst was considered feasible since the controlled breakage and particle sizing would involve extensive grinding and sieving to obtain selective and reproducible samples having similar surface areas. It has been shown that the greater the surface area, the greater and more rapid will be the metals release. Thus, it can be expected and demonstrated that positive results with unbroken catalysts can be enhanced by increasing surface area. Studies on the effect of catalyst surface area were continued in conjunction with the progressive development of the optimized microbial metal releasing system. Since THF has proven to be a superior solvent system as judged by metal release, research concentrated on using THF as the solvent system which allowed work to proceed rapidly. Also, changing the oxidation state of the metals within the 
catalyst matrix took on new importance as hydrogen peroxide shows promise as a pre-treatment solvent which also acts as a metals releasing agent. These studies include measurements of metal release at various catalyst/media ratios. The importance of the catalyst/media ratios assumed a greater importance since it is desired to reduce the media volume to the lowest level possible while still retaining good metals release. To maintain continuity and demonstrate the rational for the experiments performed in the last quarter, the results from last report are included herein followed by the results for this quarter starting with test number 44 .

\section{Methodology}

The solvent washed catalysts were examined in a series of controlled studies of microbial growth curve data versus observed metal release using a carbon source selected from the previously tested multiple fermentative carbon sources. Previous work has shown that many carbon sources can be used to enhance the metals releasing capabilities of the denitrifying cultures. Thus, the selection of the carbon source would be governed by a series of parameters involving cost and availability considerations in addition to increased growth efficiency. The carbon source selected was citrate because it results in microbial growth enhancement and its ability as a chelating agent. The effect of metabolizable chelating sources in the growth media was studied and their impact on the observed molydenum and nickel release determined. It has been found that chelators (such as citrate and EDTA) will cause initial rapid release of the metals. This chelating effect confers an added advantage to the biological releasing system and was more fully investigated.

Multiple microbial metal releasing experiments with a series of comparative growth systems were established. The basic growth medium (Table 1) was supplemented with various carbon sources and catalyst loadings as well as a trace metal solution (Table 2). All cultures were incubated at $30^{\circ} \mathrm{C}$. The growth studies were conducted with THF solvent extracted catalyst and with various concentrations of media additions and include various tests of catalyst-media ratios. Metals released at shorter time periods (every two days) were determined and comparative responses related to microbial growth (turbidity), $\mathrm{pH}$ changes, and gas production. 
TABLE 1

MEDIUM B

$1.0 \mathrm{~g} \mathrm{KH}_{2} \mathrm{PO}_{4}$

$1.8 \mathrm{~g} \mathrm{Na}_{2} \mathrm{HPO}_{4}$

$10.0 \mathrm{~g} \mathrm{NH}_{4} \mathrm{NO}_{3}$

$5.0 \mathrm{~g} \mathrm{Na} 3$ Citrate

$1.0 \mathrm{ml} \mathrm{SL}-4$ trace metals (See Table 2)

$1 \mathrm{~L} \mathrm{dH_{2 } \mathrm { O }}$

Used for growing bacteria in the presence of catalyst

NOTE: $\quad$ For lactate and isopropanol growth medium, substitute $5 \mathrm{~g}$ Na Lactate or $5 \mathrm{ml}$ isopropanol for $\mathrm{Na}$ Citrate and experiments in the last quarter employed medium $B$ in which the citrate concentration and ammonium nitrate concentration were elevated to 1 and $1.5 \%$ respectively.

TABLE 2

SL-4 Trace Metals (500X)

$\begin{array}{lc}\text { Chemical Component } & \mathrm{mg} / 1 \\ \text { EDTA, di Na salt } & 500 \\ \mathrm{FeCl}_{2} \cdot 5 \mathrm{H}_{2} \mathrm{O} & 100 \\ \mathrm{MnCl}_{2} \cdot 4 \mathrm{H}_{2} \mathrm{O} & 25 \\ \mathrm{CuCl}_{2} \cdot 2 \mathrm{H}_{2} \mathrm{O} & 10 \\ \mathrm{CoCl}_{2} \cdot 6 \mathrm{H}_{2} \mathrm{O} & 20 \\ \mathrm{NiCl}_{2} \cdot 6 \mathrm{H}_{2} \mathrm{O} & 20 \\ \mathrm{Na}_{2} \mathrm{MoO}_{4} \cdot 2 \mathrm{H}_{2} \mathrm{O} & 30 \\ \mathrm{Na}_{2} \mathrm{WO}_{4} & 5 \\ \mathrm{Na}_{2} \mathrm{SeO}_{3} & 5 \\ \mathrm{H}_{3} \mathrm{BO}_{3} & 25\end{array}$

Thermophilic pure cultures were obtained from the American Type Culture Collection (Bacillus stearothermophilus ATCC 12016) and the cultures were grown at $60^{\circ} \mathrm{C}$ for metal releasing studies. It was later noted that higher levels of catalyst were inhibitory for growth of this thermophile, therefore strain development for tolerance to catalyst was being undertaken. Strain tolerance has not been successfully developed yet. A culture of Metallosphaera sedula was obtained from Dr. Thomas Clark (DOE-PETC) in order to determine if this microorganism had the capability of anaerobic growth under denitrifying conditions. We have not been able to grow Metallosphaera sedula under denitrifying conditions and have had 
difficulties reviving this culture under aerobic conditions. We had hoped to obtain the thermophilic denitrifying strains FV-A and ITI 382-H-90 from Dr. Jacob Kristjansson (Institute of Biology, University of Iceland) in order to test the metal releasing capabilities of these bacteria isolated from Icelandic hot springs and we obtained a sampling permit from the U.S. Park Service so that we could use enrichment cultures for thermophilic denitrifiers using Yellowstone National Park hot spring algal-bacterial mat material as a source of inocula. In addition, Dr. Pieter Visscher, USGS, Menlo Park, CA kindly consented to supplying us with a culture of his unique marine denitrifier (ASN-1) which degrades alkyl sulfides so that this organism can be tested for its ability to release metals from spent coal liquefaction catalysts.

All work will centered on development of a low cost process system having optimum metal (molydenum) releasing capabilities for initiation of preliminary economic evaluation studies.

The effectiveness of the heterotrophic denitrifying bacteria to remove the nickel and molydenum at high rates and for the system to operate efficiently at small volumes was further defined to develop a practical and cost effective processing system for coal liquefaction catalysts.

Data from several of the tests conducted since the last quarterly report are summarized below in the text and in some cases are reported in tabular form. Each test was designed to provide insights into several parameters that might be important for metals release and are numbered in chronological order. Tabular data will be presented for molybdenum and nickel release. Except where noted, tests employed $100 \mathrm{ml}$ of medium contained in capped prescription bottles and solubilized metals were analyzed by atomic adsorption after media ultrafiltration to remove cell biomass and catalyst debris.

In this last quarter a new culture transfer/rejuvenation procedure was adopted wherein mixed denitrifying cultures were transferred every 3 to 4 days into fresh medium of a composition which duplicated the culture conditions which would probably be used in specific tests. This rejuvenation medium always contained $1.0 \mathrm{~g}$ of spent THF washed catalyst. This new procedure led to faster and greater levels of Mo release than has been seen in the past.

\section{Test Results}

It was found that initial and rapid metal release was due to the chelating power of the citrate medium followed by increased release due to microbial growth. Metal release by microbial growth was slower than the initial chelating effect and a preferential release of the molydenum was evident. Tests involving the ability of cultures which have been refortified with rejuvenated nutrient supplementation to release more metals were undertaken. In addition, the effects of non chelating 
carbon sources such as lactate to enhance microbial growth, but which have no chelating power, were compared to comparable growth media employing citrate.

Data from a representative, newly initiated experiment (only several days old) is provided in Table 3 below as an illustration of the efforts to define optimum economic operational parameters.

TABLE 3

Comparative Mo Release in Presence of Isopropanol and THF Washed Catalysts

$\%$ Mo Released After 11 Days

\begin{tabular}{|c|c|c|}
\hline Sample & $\begin{array}{c}\text { Isopropanol } \\
\text { Washed Shell 324 }\end{array}$ & $\begin{array}{c}\text { THF } \\
\text { Washed Shell 324 }\end{array}$ \\
\hline 1 & 18.5 & 24.6 \\
\hline $2 \mathrm{~A}$ & 31.4 & 48.5 \\
\hline $2 \mathrm{~B}$ & 27.2 & 47.2 \\
\hline 3 & 36.4 & 62.6 \\
\hline 4 & 33.7 & 56.8 \\
\hline 5 & 24.1 & 34.0 \\
\hline 6 & 28.7 & 40.0 \\
\hline 7 & 27.2 & 39.7 \\
\hline 8 & 29.0 & 36.7 \\
\hline
\end{tabular}

\section{Sample}

$1 \quad 3.0 \mathrm{~g}$ cat in $\mathrm{H}_{2} \mathrm{O}$

$2 \mathrm{~A} \quad 3.0 \mathrm{~g}$ cat in citrate media

$2 \mathrm{~B} \quad$ Same as $2 \mathrm{~A}$, but media rejuvenated at day 7

$3 \quad 1.5 \mathrm{~g}$ cat in citrate media

$4 \quad 5.0 \mathrm{~g}$ cat in citrate media

$5 \quad 3.0 \mathrm{~g}$ cat in isopropanol media

$6 \quad 3.0 \mathrm{~g}$ cat in lactate media

$7 \quad 1.5 \mathrm{~g}$ cat in thermophilic culture at $60^{\circ} \mathrm{C}$

$8 \quad 3.0 \mathrm{~g}$ cat in thermophilic culture at $60^{\circ} \mathrm{C}$

\section{Test 1 Results}

Test 1 was designed primarily to determine if the alteration of components of the medium employed (see Table 1), or changing the levels of catalyst treated, affected metals release. It is evident from the data presented in Table 4 that several variables affect the release of Mo from the catalyst (see Table 4 below). In general, the greatest percentage of Mo was released when the catalyst/media ratio was lowest and citrate levels were higher than the medium recipe outlined previously in Table 1. Varying the levels of nitrate in the medium had little effect for the release of Mo 
in these cultures and overall best release for $\mathrm{Mo}$ and $\mathrm{Ni}$ from the catalyst occurred in the culture employing $1.0 \%$ citrate and $1.5 \%$ nitrate. Bottles were monitored for metals release for up to 24 days after inoculation. While higher percentages of Mo were released at 24 days, the increase in percentage Mo released was never more than $10 \%$ higher (data not shown) than after 10 days. Therefore, a 10 day incubation after inoculation was chosen as an appropriate sample time frame for examining incubation parameters.

TABLE 4

Test 1

\% Mo Released After 10 Days Under Various Culture Conditions

\begin{tabular}{|c|c|c|c|c|c|}
\hline Sample & Media & $\begin{array}{c}\text { Grams } \\
\text { Catalyst }\end{array}$ & $\begin{array}{c}\text { \% } \\
\text { Citrate }\end{array}$ & \% NH 4 NO3 & $\begin{array}{c}\text { \% Mo } \\
\text { Released }\end{array}$ \\
\hline 1 & Medium B & 1.5 & - & - & 55 \\
\hline 2 & Medium B & 3.0 & - & - & 46 \\
\hline 3 & Medium B & 5.0 & - & - & 43 \\
\hline 4 & Medium B & 10.0 & - & - & 39 \\
\hline 5 & Altered Medium B & 3.0 & 0.25 & 1.0 & 38 \\
\hline 6 & Altered Medium B & 3.0 & 0.75 & 1.0 & 47 \\
\hline 7 & Altered Medium B & 3.0 & 1.0 & 1.0 & 47 \\
\hline 8 & Altered Medium B & 3.0 & 0.5 & 1.5 & 43 \\
\hline 9 & Altered Medium B & 3.0 & 0.5 & 0.5 & 43 \\
\hline 10 & Altered Medium B & 3.0 & 0.25 & 1.5 & 34 \\
\hline 11 & Altered Medium B & 3.0 & 0.25 & 0.5 & 38 \\
\hline 12 & Altered Medium B & 3.0 & 1.0 & 1.5 & 47 \\
\hline
\end{tabular}

* Medium $\mathrm{B}$ altered by changing levels of catalyst, citrate and $\mathrm{NH}_{3} \mathrm{NO}_{3}$

\section{Test 2 Results}

One parameter investigated in Test 2 was particularly revealing because it showed that (see Table 5 below) more Mo is leached from the spent catalyst as a result of bacterial growth versus an uninoculated blank control. Also, more Mo was released when growth occurred in the presence of nitrate as opposed to the chloride ion suggesting that denitrifying growth promotes Mo release. In general, higher turbidity readings correlated with increased Mo release, whereas, it was surprising that bacterial growth conferred no added $\mathrm{Ni}$ release suggesting that $\mathrm{Ni}$ release is preferentially influenced chemically. Ni release was no greater for bottles exhibiting good growth and no increase in Ni release was observed after three days (data no shown). These data support the idea that $\mathrm{Ni}$ is preferentially chemically leached. These results confirm previous experiments that Mo release paralleled bacterial growth, and the majority of the Mo release occurred within 10 days. 
TABLE 5

Test 2

Comparison of Metal Release and Microbial Growth

$\%$ Mo and Ni Released After 10 Days* and Turbidity

\begin{tabular}{|c|l|c|c|c|c|}
\hline Sample & \multicolumn{1}{|c|}{ Media } & $\begin{array}{c}\text { Aerobic/ } \\
\text { Anaerobic }\end{array}$ & $\begin{array}{c}\% \text { Mo } \\
\text { Release }\end{array}$ & $\begin{array}{c}\% \text { Ni } \\
\text { Release }\end{array}$ & Turbidity \\
\hline 1 & Citrate B & Aerobic & 47.9 & 13.1 & 0.72 \\
\hline 2 & Citrate B - Uninoculated & Aerobic & 30.5 & 29.1 & 0.04 \\
\hline 3 & Lactate B & Aerobic & 19.0 & 3.2 & 0.15 \\
\hline 4 & Lactate B - Uninoculated & Aerobic & 30.0 & 11.6 & 0.02 \\
\hline 5 & Water Blank & Aerobic & 28.3 & 11.6 & 0.01 \\
\hline 6 & Citrate B NH4Cl (as N Source) & Aerobic & 27.9 & 13.3 & 0.36 \\
\hline 7 & Citrate B NH4Cl - Uninoculated & Aerobic & 37.4 & 27.6 & 0.04 \\
\hline 8 & Citrate B & Anaerobic & 46.0 & 14.5 & 0.36 \\
\hline 9 & Citrate B - Uninoculated & Anaerobic & 28.0 & 27.5 & 0.04 \\
\hline 10 & Lactate B & Anaerobic & 29.7 & 12.9 & 0.11 \\
\hline 11 & Lactate B - Uninoculated & Anaerobic & 29.6 & 11.5 & 0.05 \\
\hline 12 & Water Blank & Anaerobic & 30.1 & 11.6 & 0.05 \\
\hline 13 & Citrate B NH4Cl (as N Source) & Anaerobic & 30.7 & 13.8 & 0.24 \\
\hline 14 & Citrate B 0.25\% Citrate & Anaerobic & 39.6 & 13.5 & 0.44 \\
\hline 15 & Citrate B 025\% Citrate Uninoculated & Anaerobic & 37.4 & 11.9 & 0.04 \\
\hline 16 & Citrate B 0.75\% Citrate & Anaerobic & 38.8 & 27.3 & 0.78 \\
\hline 17 & Citrate B 0.75\% Citrate Uninoculated & Anaerobic & 29.1 & 31.3 & 0.06 \\
\hline 18 & Citrate B 1.0\% Citrate & Anaerobic & 29.4 & 32.4 & 0.50 \\
\hline 19 & Citrate B 1.0\% Citrate Uninoculated & Anaerobic & 19.6 & 29.1 & 0.04 \\
\hline
\end{tabular}

* All bottles received $150 \mathrm{ml}$ media or water and 1.5 grams catalyst

Test 3 and 4

Test 3 and 4 confirmed the findings in test 2 that all Ni release occurred by day three and in some cases uninoculated controls exhibited more $\mathrm{Ni}$ in solution than in bottles where good growth had occurred (data not shown). It is possible that more $\mathrm{Ni}$ was released from the spent catalyst in cases of good growth, but was not revealed in our analysis procedure because some of the solubilized $\mathrm{Ni}$ might have been incorporated into bacterial enzyme complexes. Experiments investigating this possibility indicate that someNi is associated with the cell biomass or possible redeposition of $\mathrm{Ni}$ on the catalyst occurred. 
Test 5

In this experiment, the thermophilic culture $\underline{B}$. stearothermophilus (ATCC 12016) was grown at $60^{\circ} \mathrm{C}$ in a simple defined minimal salts medium and no Mo or $\mathrm{Ni}$ release above an uninoculated control could be demonstrated. This minimal salts medium contained $\mathrm{MgSO}_{4}$ such that, during growth, the sulfate instead of the metal sulfides were used as a source of nutritional sulfur. It was noted previously that higher levels of the spent catalyst were toxic for growth of $\underline{B}$. stearothermophilus in the absence of $\mathrm{MgSO}_{4}$ and attempts are currently underway to develop catalyst tolerant strains. While a previous experiment did show thermophilic metals release (Table 3), that experiment was conducted in a rich undefined medium and was not compared to a parallel uninoculated control.

\section{Test 6}

The experiments in test 6 were designed to reconfirm the differences in the kinetics of metals release between $\mathrm{Mo}$ and $\mathrm{Ni}$ as well as to compare release between aerobically and anaerobically grown cultures (Table 6). Test 6 also showed the metal releasing capabilities of enrichment cultures developed in this laboratory. These enrichment cultures were started using soil from near our laboratory as a source of enrichment inoculum. The cultures were enriched using citrate $B$ as the enrichment medium and reduced metal sulfides $(\mathrm{Cu}, \mathrm{Mo} \mathrm{Fe}$ and $\mathrm{Ni}$ sulfides) as the only source of nutritional sulfur. Earlier test were confirmed that crushed catalyst gave the greatest percentage Mo release. Also, while Mo release continued with time, levels of solubilized $\mathrm{Ni}$ actually decreased with time especially in aerobically grown cultures

TABLE 6

$\%$ Mo and Ni Released After 4 and 7 Days

\begin{tabular}{|c|l|c|c|c|c|c|}
\hline Sample & \multicolumn{1}{|c|}{ Inocula } & Conditions & $\begin{array}{c}\text { Mo } \\
\text { 3 Days }\end{array}$ & $\begin{array}{c}\text { Mo } \\
\text { Z Days }\end{array}$ & $\begin{array}{c}\text { Ni } \\
\text { 3 Days }\end{array}$ & $\begin{array}{c}\text { Ni } \\
\text { 7 Days }\end{array}$ \\
\hline 1 & Mixed Denitrifiers & Capped + & 10.7 & 19.2 & 10.0 & 4.4 \\
\hline 2 & Uninoculated & Capped + & 4.2 & 18.2 & 2.4 & 16.3 \\
\hline 3 & Mixed Denitrifiers & $\begin{array}{c}\text { Capped } \\
\text { Crushed Catalyst }\end{array}$ & 34.3 & 49.0 & 21.4 & 18.2 \\
\hline 4 & Mixed Denitrifiers & Anaerobic & 28.2 & 33.6 & 9.3 & 7.3 \\
\hline 5 & Mixed Denitrifiers & $\begin{array}{c}\text { Aerobic / } \\
\text { Not Agitated }\end{array}$ & 23.6 & 37.8 & 9.2 & 0.4 \\
\hline 6 & Enrichment Culture & Anaerobic & 28.0 & 33.2 & 20.8 & 16.8 \\
\hline 7 & Enrichment Culture & Aerobic & 27.8 & 40.3 & 20.3 & 5.9 \\
\hline
\end{tabular}

* All bottles received $150 \mathrm{ml}$ liquid, 1.5 grams catalyst.

+ Bottle closed but not air tight. 


\section{Test 7}

Experiments conducted in test 7 investigated some further medium parameters that were thought might influence metals release (Table 7). The standard medium, citrate B (see Table 1) was modified to contain different levels of citrate, nitrate, or a medium component not normally present, EDTA. Again it can be seen that growth (versus uninoculated controls) generally promoted good Mo release, and the presence of EDTA or higher levels of citrate showed higher levels of solubilized $\mathrm{Ni}$ after ten days of incubation.

TABLE 7

Effect of Media Composition and Chelating Agents on Metal Release $\%$ Mo and Ni Released After 10 Days

\begin{tabular}{|c|c|c|c|}
\hline & & \multicolumn{2}{|c|}{ Metal Release } \\
\hline Sample & Conditions ${ }^{\circ}$ & \% Mo & $\% \mathrm{Ni}$ \\
\hline 1 & Citrate $\mathrm{B}^{+} 0.1 \%$ EDTA Combined Denitrifiers * & 32.3 & 32.7 \\
\hline 2 & $0.1 \%$ EDTA only - NO Inoculum & 5.1 & 35.9 \\
\hline 3 & $1.0 \%$ Citrate, $1.5 \% \mathrm{NO}_{3}$ Combined Denitrifiers & 31.6 & 32.2 \\
\hline 4 & $1.0 \%$ Citrate $1.5 \% \mathrm{NO}_{3} \mathrm{No}$ Inoculum & 14.3 & 36.2 \\
\hline 5 & Like Condition 3, but $0.1 \%$ EDTA & 31.6 & 35.6 \\
\hline$\overline{6}$ & Like Condition 4 , but $0.1 \%$ EDTA & 13.2 & $\overline{33.0}$ \\
\hline 7 & Citrate B, but $0.25 \%$ Citrate & 27.5 & 14.0 \\
\hline 8 & Like Condition 7 , but No Inoculum & 26.7 & 13.9 \\
\hline 9 & Citrate B, but $0.75 \%$ Citrate & 35.8 & 13.2 \\
\hline 10 & Like Condition 9 , but No Inoculum & 17.9 & 35.4 \\
\hline 11 & Citrate $B$, but $1.0 \%$ Citrate & 32.0 & 31.1 \\
\hline 12 & Like Condition 11, but No Inoculum & $\overline{13.4}$ & $\overline{35.4}$ \\
\hline
\end{tabular}

- All bottles capped (facultatively anaerobic).

+ See Table 1.

* Previous denitrifiers combined with enrichment cultures.

\section{Test 8}

Experiments were conducted in test 8 to determine the abiotic release of Mo and $\mathrm{Ni}$ under conditions of no microbial growth, but carried out in Citrate Bm medium testing pH regimes from $\mathrm{pH} 5$ to 9 (Table 8). This test demonstrated greater levels of Mo and Ni release correlated with more acidic conditions or lower $\mathrm{pH}$. However, this $\mathrm{pH}$ test is currently being repeated in water only because preliminary findings from a currently run nitric acid leach indicate that the citrate present in the citrate $\mathrm{Bm}$ medium used in this test probably contributed to metals release. 
Test 9

Test 9 was conducted to determine if varying levels of citrate at constant $\mathrm{pH}$ contributed to abiotic metals release. Generally, it appeared that higher levels of citrate led to greater $\mathrm{Ni}$ release, but led to a much greater decrease in Mo release. This latter result, the decrease in Mo release with increasing citrate levels, can not presently be adequately explained.

TABLE 8

Effect of $\mathrm{pH}$ on Abiotic ${ }^{\mathrm{a}}$ Metals Release

$\%$ Mo and Ni Released After 21 Days

\begin{tabular}{|c|c|c|c|}
\hline \multicolumn{2}{|c|}{} & \multicolumn{2}{|c|}{ Metal Release } \\
\hline Sample & $\mathrm{pH}$ & \% Mo & \% Ni \\
\hline 1 & 5 & 51.36 & 72.12 \\
\hline 2 & 6 & 45.9 & 72.61 \\
\hline 3 & 7 & 39.4 & 59.3 \\
\hline 4 & 8 & 42.2 & 57.55 \\
\hline 5 & 9 & 40.0 & 41.3 \\
\hline
\end{tabular}

a Test was conducted in standard Citrate Bm Medium with azide added to prevent growth

\section{TABLE 9}

Effect of Varying Citrate Levels on Abiotica Metal Release $\%$ Mo and Ni Released After 21 Days

\begin{tabular}{|c|c|c|c|}
\hline \multicolumn{2}{|c|}{} & \multicolumn{2}{|c|}{ Metal Release } \\
\hline Sample & \% Citrate & \% Mo & \% Ni \\
\hline 1 & 0.5 & 40.0 & 63.0 \\
\hline 2 & 1.0 & 30.0 & 67.0 \\
\hline 3 & 2.5 & 10.0 & 68.0 \\
\hline 4 & 5.0 & 10.0 & 68.5 \\
\hline 5 & 10.0 & 15.0 & 69.0 \\
\hline
\end{tabular}

a Test was conducted in standard Citrate Bm with varying levels of citrate and azide added to prevent growth

Test 10

Test 10 was conducted to determine if sulfate (as a sulfur source in the medium), and three days pregrowth had an effect on metals release from spent, THF washed Shell 324 catalyst. A very interesting result (which had been noted 
previously) was found for $\mathrm{Ni}$ release in conditions of microbial growth versus conditions of no microbial growth due to the inhibitory effects of azide. In looking at the data (see Table 10), it would appear that either azide promotes Ni release or that microbial growth inhibits $\mathrm{Ni}$ release as measured on day 21 . However, earlier measurements (data not shown) at day 2, 5, 7 etc. indicated a rapid Ni release followed by a gradual decline in measured levels of $\mathrm{Ni}$ to the levels seen at day 21 shown in Table10. This same phenomenon had been seen in prior tests also. Mass balance studies to determine the fate of the released $\mathrm{Ni}$ in systems where microbial growth occurs were run (see below). One possible explanation of the $\mathrm{Ni}$ disappearance involves $\mathrm{Ni}$ uptake by the denitrifiers or cell wall sorption such that upon sample sub-micron filtration prior to sample analysis, the $\mathrm{Ni}$ is retained by the filter. Again it can be seen that greater Mo release occurs in cases of microbial growth, and, in this experiment, higher levels of citrate led to greater levels of Mo release in both growth and non growth conditions. No conclusions about pregrowth or the effect of sulfate on metals release can be made at this time.

\section{Test 11}

Since it is now known that denitrification can occur in the presence of oxygen and that denitrification can occur at the same time as aerobic respiration, an experiment was set up wherein air was not actively excluded (i.e. uncapped) from the culture vessel. This test was conducted to determine if oxygen had an effect on metals release. The data show (see Table 11) that after 21 days $92.6 \%$ of the Mo originally on the spent, THF washed Shell 324 was released under conditions where air was not excluded from the culture vessel. This was the highest level of Mo release noted to date for uncrushed catalyst. All cultures in this test were inoculated with our combined, mixed heterotrophic denitrifiers. Again, as noted earlier above, the percentage $\mathrm{Ni}$ released shown at day 21 is not a true representation of the $\mathrm{Ni}$ removed from the catalyst. As seen repeatedly in past experiments, and also seen in this test, microbial growth promoted greater Mo release than non-growth controls containing azide. Catalyst from sample \#1 from this test as well as catalyst from some of the previous tests reported above was saved for media rejuvenation experiments reported below. 
TABLE 10

Effect of Sulfate and 3 Days Pregrowth ${ }^{\mathrm{a}}$ on Metal Release

$\%$ Mo and Ni Released After 21 Days

\begin{tabular}{|c|l|c|c|}
\hline \multicolumn{2}{|c|}{} & \multicolumn{2}{c|}{ Metal Release } \\
\hline Sample & \multicolumn{1}{|c|}{ Condition } & \% Mo & $\%$ Ni \\
\hline 1 & Citrate A b & 51.67 & 14.03 \\
\hline 2 & Citrate A \& Azide & 41.0 & 43.0 \\
\hline 3 & Double Citrate A C & 62.87 & 38.06 \\
\hline 4 & Double Citrate A \& Azide & 59.0 & 63.0 \\
\hline
\end{tabular}

a Samples 1 and 3 were grown for 3 days prior to $1.5 \mathrm{~g}$ of catalyst being introduced.

Samples 2 and 4 were also started at that time.

b Citrate $\mathrm{A}$ is the same medium as Citrate $\mathrm{Bm}$ but supplemented with $0.5 \%$ $\mathrm{Na}_{2} \mathrm{SO}_{4}$.

c Double Citrate A contained twice the level of all media components as Citrate A.

TABLE 11

Effect of Aerobic Versus Facultatively Grown Cultures on Metal Release $\%$ Mo and Ni Released After 21 Days

\begin{tabular}{|c|c|c|c|}
\hline & & \multicolumn{2}{|c|}{ Metal Release } \\
\hline Sample & Condition & \% Mo & $\% \mathrm{Ni}$ \\
\hline 1 & Aerobic a & 92.6 & $\overline{15.42}$ \\
\hline 2 & Aerobic \& Azide & 36.0 & $\overline{60.8}$ \\
\hline$\overline{3}$ & Facultative $\mathrm{b}$ & 68.3 & 66.3 \\
\hline 4 & Facultative \& Azide & 52.0 & 65.2 \\
\hline
\end{tabular}

a $150 \mathrm{ml}$ of Citrate $\mathrm{Bm}$ in 1 liter Erlenmeyer flasks, no closure, no agitation.

b $150 \mathrm{ml}$ of Citrate $\mathrm{Bm}$ in $200 \mathrm{ml}$ bottles, loosely capped.

\section{Test 12}

Test 12 made use of catalyst previously subjected to experiments to test metals release and these catalyst samples were then tested for additional metals release after old media had been decanted and fresh media added. Table 12 identifies the samples from previous tests that were used by test number (in parentheses) followed by specific sample number. All samples received new Citrate $\mathrm{Bm}$ medium and were grown facultatively. Column 2 (First) represents metals release after the first medium rejuvenation measured after 3 days and column 3 (Second) represents metals release measured 13 days after a second round of medium rejuvenation. 
Some very interesting and notable findings resulted from this test. Most importantly, it can be seen (Table 12) that $100 \%$ of the Mo was released from the spent catalyst for sample number 6 . This is the first time we have released all of the Mo from whole uncrushed spent catalyst. It is also notable that decreasing levels of Mo were released after each rejuvenation and poor growth occurred during the final rejuvenation suggesting a limiting growth factor. After the second rejuvenation and after final measurements of metals release were made, these cultures were used to inoculate Citrate $\mathrm{Bm}$ subcultures that contained thiosulfate whereupon good growth occurred suggesting that during the second rejuvenation the cultures had become starved for a source of nutritional sulfur.

\section{Test 13}

It had been hypothesized that better Mo release might occur if the THF washed catalyst could be pretreated with a good chelating agent to remove $\mathrm{Ni}$, a metal which is known to be quite toxic to some microorganisms. In order to test this idea samples of spent THF washed catalyst were pretreated with either nitrilotriacetic acid (NTA) or Diethylenetriaminepentaacetic acid, two good chelating agents. While the chelating agents appeared to promote Ni release (See Table 13), a generally poor release of Mo occurred, and this was attributed to the poor growth that occurred in this test which might have been caused by the toxicity of any remaining cheating agent. It is notable that sample number 1 , which served as a control and had received no pretreatment with chelating agents, exhibited the best Mo release in this test. 
TABLE 12

Effect of Selective Media Rejuvenations on Metal Release $\%$ Mo and Ni Release

\begin{tabular}{|c|c|c|c|c|c|c|c|}
\hline & \multicolumn{6}{|c|}{ Metal Release } \\
\hline & & \multicolumn{2}{|c|}{ Initial b } & \multicolumn{2}{|c|}{ First $c$} & \multicolumn{2}{|c|}{ Second d } \\
\hline Sample & Condition $^{\mathrm{a}}$ & $\% \mathrm{Mo}$ & $\% \mathrm{Ni}$ & $\% \mathrm{Mo}$ & $\% \mathrm{Ni}$ & $\% \mathrm{Mo}$ & $\% \mathrm{Ni}$ \\
\hline 1 & (8) 1 & 51.36 & 72.12 & 66.43 & 81.89 & 73.8 & 85.53 \\
\hline 2 & (8) 2 & 45.9 & 72.61 & 63.71 & 83.25 & 68.77 & 86.1 \\
\hline$\overline{3}$ & (8) 4 & $\overline{42.2}$ & 57.55 & 58.53 & 71.28 & 61.62 & 73.85 \\
\hline 4 & (10) 1 & 51.67 & 14.03 & 64.84 & 45.33 & 69.25 & 46.75 \\
\hline 5 & (10) 3 & 62.87 & 38.06 & 73.72 & 56.62 & 77.55 & 64.28 \\
\hline 6 & (11) 1 & 92.64 & 15.42 & 100.77 & 28.65 & NTe & $\mathrm{NT}$ \\
\hline 7 & Controi $f$ & - & - & 41.47 & 51.66 & 50.86 & 61.67 \\
\hline
\end{tabular}

a Supernatant from previous tests $(8,10,11)$ poured off and $150 \mathrm{ml}$ new citrate $B$ (only) added. Condition $=$ test number followed by that specific test sample number.

: b \% Metal Release after 21 days in tests $8,10,11 .^{\prime}$

c \% Total Metal Release after 1st media rejuvenation after 3 days.

d \% Total Metal Release after 2nd media rejuvenation 13 days after 2nd rejuvenation.

e NT reading not taken as $100 \%$ Mo release had already occurred.

f Control started at time zero start of test 12 . ; 
TABLE 13

Effect of Chelators on Metal Release

$\%$ Mo and Ni Released After 8 and 16 Days

\begin{tabular}{|c|c|c|c|c|c|c|}
\hline \multirow[b]{2}{*}{ Sample } & \multirow[b]{2}{*}{ Condition a } & \multirow[b]{2}{*}{ Condition $\mathrm{b}$} & \multicolumn{2}{|c|}{ 8a Day Release } & \multicolumn{2}{|c|}{ 16b Day Release } \\
\hline & & & $\%$ Mo & $\% \mathrm{Ni}$ & \% Mo & $\% \mathrm{Ni}$ \\
\hline 1 & H2O Only & Citrate $\mathrm{Bm}$ & 17.0 & 21.0 & 34.0 & 41.0 \\
\hline$\overline{2}$ & H2O \& DTPA & Citrate Bm & 11.0 & 41.2 & 21.0 & 49.0 \\
\hline 3 & $\mathrm{H} 2 \mathrm{O} \&$ \&TA & Citrate $\mathrm{Bm}$ & 9.0 & 49.0 & 20.0 & 54.0 \\
\hline 4 & Citrate Bm Only & Citrate $\mathrm{Bm}$ & 21.0 & 44.0 & 30.0 & 53.0 \\
\hline 5 & Citrate Bm \& DTPA & Citrate $\mathrm{Bm}$ & 14.0 & 50.0 & 20.0 & 54.0 \\
\hline 6 & Citrate Bm NTA & Citrate $\mathrm{Bm}$ & 16.0 & 53.0 & 21.0 & 57.0 \\
\hline
\end{tabular}

a 1st 8 days no inoculum, DPTA and NTA at $1.0 \%$ concentration. Only Sample 4 received azide.

b At day 8 , supernatants were decanted and all samples rejuvenated with $150 \mathrm{ml}$ fresh, sterile Citrate $\mathrm{Bm}$ and inoculated with mixed denitrifiers. Metal release read after 8 more days.

Test 14

The high levels of Mo release seen in one condition in test 11 needed to be reconfirmed so test 14 was conducted to determine if we could duplicate those results. Again, it can be seen (Table 14) that the greatest Mo release occurred in the culture condition where air was not actively excluded. Interestingly, more Mo release occurred in the aerobic azide control (no growth) than in sample 3 which was grown facultatively suggesting that not only does microbial growth contribute to Mo release, but also that air somehow contributes to Mo release. As noted above previously, the low levels of released Ni measured at day 7 probably do not reflect the true amount of Ni released from the spent catalyst.

TABLE 14

Effect of Aerobic Versus Facultatively Conditions on Metal Release $\%$ Mo and Ni Released After 7 Days

\begin{tabular}{|c|l|c|c|}
\hline \multicolumn{2}{|c|}{ Condition } & \multicolumn{2}{c|}{ Metal Release } \\
\hline Sample & \multicolumn{1}{|c|}{ \% Mo } & \% Ni \\
\hline 1 & Aerobic $^{\text {a }}$ & 71.0 & 6.81 \\
\hline 2 & Aerobic \& Azide & 57.55 & 64.63 \\
\hline 3 & Facultative b & 44.34 & 46.60 \\
\hline 4 & Facultative \& Azide & 22.56 & 56.22 \\
\hline
\end{tabular}

a $150 \mathrm{ml}$ of Citrate $\mathrm{Bm}$ in $0.5 \mathrm{~L}$ Erlenmeyer flasks, no closure, no agitation.

b $150 \mathrm{ml}$ of Citrate $\mathrm{Bm}$ in $200 \mathrm{ml}$ bottles, loosely capped. 
Test 15 was conducted to try and relate growth conditions, $\mathrm{pH}$, turbidity and different sets of inocula to metals release. Table 15 gives tabular results for Mo release at day 7 and day 14 and tabular results for Ni release at day 7 only. Figures 1 through 9 give a more detailed graphic view showing measurements made for Mo release, $\mathrm{pH}$ and turbidity for each sample condition. Interestingly, there was not a great deal of difference in the measured levels of Mo release between the different sample conditions except for the no growth azide controls. Generally, Mo release lagged behind growth (turbidity) and the $\mathrm{pH}$ increased over time except for the " $\mathrm{N}$ " series. It is not known why the absence of active air exclusion (aerobic series) did not lead to greater Mo release in this experiment. 
TABLE 15

Effect of Different Inocula and Culture Conditions on Metal Release $\% \mathrm{Mo}$ and Ni Release

\begin{tabular}{|c|c|c|c|c|c|}
\hline \multirow[b]{2}{*}{ Sample } & \multirow[b]{2}{*}{ Condition } & \multicolumn{2}{|c|}{ Day 7} & \multicolumn{2}{|c|}{ Day 14 } \\
\hline & & \% Mo & $\% \mathrm{Ni}$ & $\% \mathrm{Mo}$ & $\% \mathrm{Ni}$ \\
\hline $1 \mathrm{~A}$ & Aerobic ${ }^{b}$ & 54.22 & 24.69 & 54.67 & $\mathrm{ND}^{*}$ \\
\hline $2 \mathrm{~A}$ & Aerobic $^{b}$ & 54.47 & 24.49 & 54.29 & ND \\
\hline$\overline{3 \mathrm{~A}}$ & Aerobic ${ }^{b}$ & 56.05 & 39.59 & 58.83 & ND \\
\hline $4 \mathrm{~A}$ & Aerobic ${ }^{b}$ & 57.67 & 30.52 & 56.53 & ND \\
\hline$\overline{5 A}$ & Aerobicb & 56.35 & 27.92 & 56.50 & ND \\
\hline$\overline{6 A}$ & Aerobic ${ }^{b}$ & 28.73 & 43.56 & 29.95 & ND \\
\hline $1 \bar{F}$ & Facultative ${ }^{C}$ & 49.52 & 29.04 & 55.77 & ND \\
\hline $2 \mathrm{~F}$ & Facultative $^{c}$ & 50.31 & 30.33 & 59.86 & $\overline{N D}$ \\
\hline $3 \mathrm{~F}$ & Facultative & 43.97 & 35.51 & 54.63 & ND \\
\hline$\overline{4 F}$ & $\overline{\text { Facultative }^{c}}$ & 52.13 & 30.30 & 56.08 & $\overline{\mathrm{ND}}$ \\
\hline $5 F$ & Facultative $^{c}$ & 48.65 & 32.74 & 49.91 & ND \\
\hline $6 \mathrm{~F}$ & Facultative ${ }^{c}$ & 24.49 & 38.09 & 24.95 & ND \\
\hline$\overline{1 N}$ & Anaerobic ${ }^{d}$ & 43.80 & 42.08 & 52.20 & $\overline{\mathrm{ND}}$ \\
\hline $2 \mathrm{~N}$ & Anaerobicd & 38.60 & 39.92 & 47.28 & ND \\
\hline $3 \mathrm{~N}$ & Anaerobic ${ }^{\mathrm{d}}$ & 40.15 & 39.75 & 51.83 & ND \\
\hline $4 \mathrm{~N}$ & Anaerobicd & 42.47 & 39.89 & 50.29 & ND \\
\hline $5 \mathrm{~N}$ & Anaerobicd & 39.94 & 39.61 & 49.43 & $\mathrm{ND}$ \\
\hline $6 \mathrm{~N}$ & Anaerobic ${ }^{d}$ & 25.98 & 37.92 & 35.32 & ND \\
\hline
\end{tabular}

a All sample "1" inoculated newly enriched mixed denitrifiers.

Sample "2" inoculated with a mix of all heterotrophic denitrifiers.

Sample "3" inoculated with old, stored heterotrophic denitrifiers.

Sample "4" as Sample "1", but pregrown on a spent catalyst other than shell 324

Sample "5" Inoculum was equal mix of all of above.

Sample "6" No inoculum, azide control.

b $150 \mathrm{ml}$ of Citrate $\mathrm{Bm}$ in $250 \mathrm{ml}$ Erlenmeyer flasks, no closure, no agitation.

c $150 \mathrm{ml}$ of Citrate $\mathrm{Bm}$ in $200 \mathrm{ml}$ bottles, loosely capped.

d $150 \mathrm{ml}$ of Citrate $\mathrm{Bm}$ in $200 \mathrm{ml}$ bottles, prepared in an anaerobic chamber and tightly sealed.

* Not Determined 
Test 16

This test was conducted to determine if the mixed heterotrophic denitrifiers could grow in the presence of unwashed, spent Shell 324 and promote metals release. Interesting, all the cultures grew well, but $\mathrm{Mo}$ and $\mathrm{Ni}$ release was very poor (data not shown). A possible explanation for this is provided below.

\section{Test 17}

Test 17 was designed to help define the inhibitory effects of coal liquids on Mo release as test 16 had shown very poor metals release from unwashed catalyst. Sample conditions compared a control (Sample 1-Table16) which was THF washed catalyst inoculated with mixed, heterotrophic denitrifiers incubated facultatively to various other conditions. As has been noted many times previously, microbial growth (Sample 1) showed much greater Mo release than the no growth azide control (Sample 2). Interestingly, a culture vessel which had added coal liquids (Sample 3) showed relatively good Mo release even though the amount of coal liquids added was more than would contained in a culture vessel having unwashed catalyst which was done in parallel sample number 6 . Therefore, while it appears that coal liquids added to THF washed catalyst slightly inhibited Mo release, coal liquids already on or within spent catalyst greatly inhibited Mo release.

\section{Test 18}

Test 18 was designed to determine if delayed inoculation along with media rejuvenation affected Mo release. This test again showed that microbial growth promoted Mo release over no growth controls and suggested that delayed inoculation led to less Mo release (Table 17). 
Table 16

Effect of Added Coal Liquids on Metal Release

$\%$ Mo Released After 14 Days

\begin{tabular}{|c|l|c|}
\hline Sample & \multicolumn{1}{|c|}{ Condition $^{\mathbf{a}}$} & \% Mo Release \\
\hline 1 & Control (with denitrifier growth) & 49.55 \\
\hline 2 & Azide & 25.62 \\
\hline 3 & 0.1 ml Coal Liquids & 40.56 \\
\hline 4 & 0.1 ml Coal Liquids-No Added Catalyst & 0.81 \\
\hline 5 & No Citrate & 6.73 \\
\hline 6 & Non THF Washed Catalyst & 6.78 \\
\hline 7 & Non THF Washed Catalyst \& Azide & 7.05 \\
\hline
\end{tabular}

a All bottles contained $150 \mathrm{ml}$ Citrate $\mathrm{Bm}$ with $5 \mathrm{ml}$ inoculum of combined mixed heterotrophic denitrifiers, and 1.5g THF washed catalyst (except for sample $6 \& 7$ which had ion washed catalyst). Sample 4 contained no catalyst.

Table 17

Effect of Media Rejuvenation and Delayed Inoculation on Metal Release \% Mo Released After 14 Days

\begin{tabular}{|c|l|c|}
\hline Sample & \multicolumn{1}{|c|}{ Condition $^{\mathbf{a}}$} & $\begin{array}{c}\text { Metal Release } \\
\% \text { Mo }\end{array}$ \\
\hline 1 & Control (with denitrifier growth) & 52.49 \\
\hline 2 & Reinoculated \& New Media After 2 Days & 43.17 \\
\hline 3 & Not Inoculated \& Azide & 24.97 \\
\hline 4 & $\begin{array}{l}\text { Inoculated After 2 Days \& New Media After } \\
\text { 2Days }\end{array}$ & 40.09 \\
\hline 5 & $\begin{array}{l}\text { Never Inoculated \& New Media After 2 } \\
\text { Days }\end{array}$ & 6.73 \\
\hline
\end{tabular}

a All bottles contained $150 \mathrm{ml}$ Citrate $\mathrm{Bm}$ and $1.5 \mathrm{~g}$ THF Washed Catalyst. 
Test 19

It had been suggested the no growth conditions achieved by adding azide might lead to erroneous levels of Mo released by some unknown chemical interaction of the catalyst and the azide. Therefore, test 19 was performed to determine if another means of achieving sterility, autoclaving, could be used for no growth controls. It can be seen (Table 18) that unautoclaved catalyst released more Mo than catalyst which had been previously autoclaved and slightly less Mo was released in the autoclaved azide control compared to the unautoclaved azide control.

Table 18

Effect of Autoclaving Catalyst on Metal Release \% Mo Released After 14 Days

\begin{tabular}{|c|l|c|}
\hline Sample & \multicolumn{1}{|c|}{ Condition $^{\mathbf{a}}$} & $\begin{array}{c}\text { Metal Release } \\
\% \text { Mo }\end{array}$ \\
\hline 1 & Autoclaved, Cooled, Inoculated & 43.05 \\
\hline 2 & Autoclaved, Cooled, Inoculated \& Azide & 25.37 \\
\hline 3 & Unautoclaved, Inoculated & 51.83 \\
\hline 4 & Unautoclaved, Inoculated \& Azide & 26.36 \\
\hline
\end{tabular}

a All bottles contained $150 \mathrm{ml}$ Citrate $\mathrm{Bm}, 1.5 \mathrm{~g}$ THF Washed Catalyst. All were inoculated with $5 \mathrm{ml}$ of combined, mixed, heterotrophic denitrifiers.

Test 20

Test 20 was designed to determine if microbial growth per se is a requisite condition for solubilization of Mo and Ni from spent Shell 324 catalyst. Controls were compared to conditions where cells had been pregrown in the presence of catalyst or without catalyst plus thiosulfate and the resulting turbid supernatant was ultra filtered to render it cell free and challenged with fresh catalyst. Table 19 (below) shows the results of this experiment. As has been noted numerous times in past work Mo release is promoted by microbial growth and cell-free supernatant has the ability to release metals. However, while pregrowth on thiosulfate had little effect on nickel release, it appeared that pregrowth on catalyst resulted in a cell-free supernatant that released Mo better than the corresponding thiosulfate pregrowth supernatant. It again appeared that microbial growth (sample 4) retarded $\mathrm{Ni}$ release as noted in past work, but this was later defined in mass balance experiments as a redeposition of solubilized $\mathrm{Ni}$ back onto the catalyst matrix. 
Table 19

Activity of Cell-Free Supernatant for Metal Release

$\%$ Mo and Ni Released After 13 Days

\begin{tabular}{|c|l|c|c|}
\hline Sample & \multicolumn{1}{|c|}{ Condition } & \% Mo Release & \% Ni release \\
\hline 1 & pregrown thiosulfate & 37.23 & 32.88 \\
\hline 2 & pregrown catalyst & 53.64 & 36.82 \\
\hline 3 & control azide & 22.30 & 45.11 \\
\hline 4 & control with growth & 45.82 & 11.35 \\
\hline
\end{tabular}

Test 21

Test 21 further investigated the inhibitory effects of thiosulfate on metals release during microbial growth in the presence of catalyst as well as an additional test of metals release on crushed versus whole catalyst. After 8 days of growth, crushed and whole catalyst yielded $70 \%$ and $38 \%$ Mo release respectively. In the presence of thiosulfate, Mo release was retarded by about $10 \%$. Interestingly, thiosulfate appeared to have little effect on $\mathrm{Ni}$ release and $\mathrm{Ni}$ redeposition on the catalyst matrix (to be discussed later) did not occur using crushed catalyst ( see Table 20 below).

Table 20

Effect of Thiosulfate on Metals Release

\% Metals Release After 8 Days of Growth

\begin{tabular}{|c|l|c|c|}
\hline Sample & \multicolumn{1}{|c|}{ Condition } & $\begin{array}{c}\text { \% Mo } \\
\text { Release }\end{array}$ & $\begin{array}{c}\% \mathbf{~ N i} \\
\text { release }\end{array}$ \\
\hline 1 & Control & 44.63 & 9.44 \\
\hline 2 & Azide Control & 19.90 & 40.10 \\
\hline 3 & $\begin{array}{l}0.5 \% \\
\text { Thiosulfate(TS) }\end{array}$ & 33.09 & 28.50 \\
\hline 4 & $0.5 \%$ TS + Azide & 23.74 & 37.24 \\
\hline 5 & $1.5 \%$ TS & 32.89 & 24.19 \\
\hline 6 & $1.5 \%$ TS +Azide & 26.83 & 33.63 \\
\hline 7 & Crushed & 70.27 & 55.54 \\
\hline 8 & Crushed + Azide & 37.87 & 57.75 \\
\hline
\end{tabular}




\section{Test 22}

It was reasoned that better biosolubilization of metals by microbial growth might occur if the THF Shell 324 catalyst was pretreated by nitric acid because the acid per se might leach some metals as well as alter the oxidation state of the metals in the catalyst matrix leading to better metals release during subsequent microbial growth. In this initial test, better leaching appeared to occur (data not shown), but the data was hard to interpret as the nitric acid solubilized a great deal of the aluminum support matrix which led to interference in Mo release measurements. A method for accurately measuring Mo release despite the presence of aluminum was developed and this experiment was later repeated (see below).

\section{Test 23}

Test 23 was a mass balance experiment that measured levels of $\mathrm{Mo}$ and $\mathrm{Ni}$ released after 7 days of microbial growth, either aerobically or facultatively, and also measured metals retained on the catalyst in an effort to account for all the metals. No metals were detected that might have been retained with cell biomass after micro filtration of sample aliquots prior to AA analysis. An Inorganic Ventures procedure was used to analyze the filters to prepare samples of culture supernatants for testing and was also used to analyze total metals content of the catalyst after the 7 days of microbial growth. It can be seen (Table 21) that in all cases close to $100 \%$ of the metals could be accounted for. It had been noted in the past that during the course of an experiment, solubilized levels of $\mathrm{Ni}$ in the supernatant rose then declined during the period of microbial growth. From the data gathered in this experiment, it now appears that solubilized $\mathrm{Ni}$ is redeposited upon the catalyst matrix during the course of microbial growth.

Table 21

\% Metals Solubilized or Retained in Catalyst After 7 Days of growth

\begin{tabular}{clcccc} 
& & \multicolumn{2}{c}{$\%$ Mo } & \multicolumn{2}{c}{ \% Ni } \\
Sample & Condition & Released & On Catalyst & Released & On Catalyst \\
1 & Aerobic & 27.77 & 71.72 & 16.27 & 80.40 \\
2 & Aerobic + Azide & 14.76 & 79.15 & 61.73 & 45.64 \\
3 & Facultative & 27.64 & 71.62 & 25.76 & 68.82 \\
4 & Facultative + Azide & 12.82 & 78.75 & 48.16 & 52.83
\end{tabular}


Test 24

Since it had been previously noted in certain experiments that more Mo was solubilized in growing cultures where air was not actively excluded (aerobic conditions), an experiment was performed to compare Mo and Ni release using cultures that were grown facultatively, aerobically and aerobically with active aeration. It can be seen (Table 22) that active aeration seemed to retard Mo release and much lower levels of solubilized $\mathrm{Ni}$ were present in the supernatant of the actively aerated culture analyzed at day 8. $\mathrm{pH}$ data is also included for this experiment (Table 23) and to illustrate the $\mathrm{Ni}$ redeposition phenomenon (discussed above) $\mathrm{Ni}$ analyses in ppm are provided for days 3,6 , and 8 of microbial growth (Table 24).

Table 22

Effect of Active Aeration on Metals Released \% Metals Released on Day 8

$\begin{array}{clcc}\text { Sample } & \text { Condition } & \text { \% Mo Released } & \text { \% Ni Released } \\ 1 & \text { Facultative } & 50.41 & 36.15 \\ 2 & \text { Facultative + Azide } & 24.07 & 34.18 \\ 3 & \text { Aerobic } & 52.25 & 16.11 \\ 4 & \text { Aerobic + Azide } & 23.11 & 38.56 \\ 5 & \text { Aerated } & 41.02 & 4.40 \\ 6 & \text { Aerated + Azide } & 29.61 & 51.99\end{array}$

Table 23

pH Data for Test 24

\begin{tabular}{|c|c|c|c|c|}
\hline Sample & Day 0 & Day 3 & Day 6 & Day 8 \\
\hline 1 & 6.89 & 6.95 & 7.04 & 7.28 \\
\hline 2 & 6.89 & 6.99 & 7.08 & 7.16 \\
\hline 3 & 6.89 & 7.20 & 7.55 & 7.12 \\
\hline 4 & 6.89 & 6.97 & 7.05 & 7.10 \\
\hline 5 & 6.89 & 8.65 & 7.54 & 7.12 \\
\hline 6 & 6.89 & 6.95 & 7.05 & 7.00 \\
\hline
\end{tabular}


Table 24

Solubilized Ni in ppm

\begin{tabular}{|c|c|c|c|}
\hline Sample & Day 3 & Day 6 & Day 8 \\
\hline 1 & 59 & 80 & 88 \\
\hline 2 & 52 & 57 & 84 \\
\hline 3 & 68 & 78 & 39 \\
\hline 4 & 64 & 87 & 105 \\
\hline 5 & 58 & 19 & 16 \\
\hline 6 & 90 & 133 & 176 \\
\hline
\end{tabular}

\section{Test 25}

Test 25 was essentially a rejuvenation experiment wherein catalyst was subjected to two rounds of microbial growth; however this test employed unwashed Shell 324 catalyst. Unwashed catalyst was used because it was thought that microbial action in the first round of growth might remove enough of the coal liquids to allow biosolubilization of the Mo and $\mathrm{Ni}$ during the subsequent round of growth where the spent medium was decanted and fresh media added. Both citrate $\mathrm{Bm}$ medium and a citrate $\mathrm{Bm}$ medium with low citrate levels $(0.25 \%)$ were employed, the idea being that limited carbon levels would increase the pressure on the microbial consortium to utilize the coal liquids as a carbon source. There were no marked differences in metals release between these two incubation conditions (data not shown) and metals release was generally less than $10 \%$ total after both rounds of growth. It appears that coal liquids removal is essential for subsequent microbial biosolubilization.

\section{Test 26}

Test 26 was set up to study the effect of $\mathrm{pH}$ alone in sterile citrate $\mathrm{Bm}$ media as it had been noted (see Test 24 above) that the $\mathrm{pH}$ of the cultures varies with time. A variety $\mathrm{pH}$ regimes were tested and $\mathrm{pH}$ was found to affect $\mathrm{Ni}$ release, but different $\mathrm{pH}$ regimes had little if no affect upon Mo release (see Table 25 below). 
Table 25

Effect of $\mathrm{pH}$ on \% Metals Release

\begin{tabular}{|c|c|c|}
\hline $\mathrm{pH}$ & \% Mo Release & \% Ni Release \\
\hline 4 & 22.60 & 16.79 \\
\hline 5 & 22.86 & 14.64 \\
\hline 6 & 23.90 & 13.35 \\
\hline 7 & 26.87 & 7.75 \\
\hline 8 & 24.93 & 1.25 \\
\hline
\end{tabular}

Test 27

Test 27 was a quite an extensive test designed to determine if a $\mathrm{Ni}$ or $\mathrm{Mo}$ releasing "factor" is produced during microbial growth, and, if so, would it function as a metal releasing agent in the absence of cells. This test also investigated if the putative metal releasing factor (MRF) is induced and produced in the culture to a greater extent if cells are grown in the presence of catalyst without an added sulfur source versus cells grown without catalyst with thiosulfate as a sulfur source. Except for the one control (sample A), all the metals release in this experiment was mediated by cell-free supernatants and secondary growth was precluded in the already grown cultures by centrifugation to obtain the cell-free supernatant, ultra microfiltration of the supernatant, and finally the addition of sodium azide. All experiments utilized citrate $\mathrm{Bm}$ medium. The following key provides the conditions of the 11 samples listed in Table 26 (see below). Metals release was followed daily for 3 days after challenging supernatant with catalyst.

\section{$\underline{\text { Key }}$}

Sample Pre-Test Growth Conditions

$1,2,3$ Grown for 2, 3, and 4 days respectively with thiosulfate, no catalyst presenta

$4,5,6$ Grown for 2,3 , and 4 days respectively with catalyst ${ }^{b}$

$7,8,9$ Grown for 2,3 , and 4 days respectively with catalystc

A Positive control, i.e. regular microbial growth

B Negative control, i.e. inoculated but no growth due to azide addition

a Supernatant challenged with fresh THF washed catalyst

b Supernatant challenged with catalyst with which the cells had been grown

c Supernatant challenged with fresh THF washed catalyst 
Table 26

Test for Metals Releasing Factor

\begin{tabular}{|c|c|c|c|c|c|c|c|c|}
\hline \multirow[b]{2}{*}{ Sample } & \multicolumn{3}{|c|}{ Mo ppm } & \multicolumn{2}{|c|}{$\%$ Total } & \multicolumn{2}{|c|}{ Ni ppm } & \multirow{2}{*}{$\begin{array}{l}\text { \% Tota } \\
\text { Day } 3\end{array}$} \\
\hline & Day 1 & Day 2 & Day 3 & Day 3 & Day 1 : & Day 2 & Day 3 & \\
\hline 1 & 192 & 209 & 198 & 24.77 & 35 & 45 & 54 & 22.11 \\
\hline 2 & 209 & 225 & 235 & 29.23 & 33 & 41 & 48 & 19.69 \\
\hline 3 & 79 & 119 & 225 & 27.08 & 17 & 21 & 40 & 16.08 \\
\hline 4 & 127 & 142 & 181 & 22.24 & 49 & 51 & 57 & 23.56 \\
\hline 5 & 186 & 235 & 243 & 27.12 & 60 & 68 & 72 & 29.33 \\
\hline 6. & 248 & 257 & 260 & 32.44 & 63 & 68 & 71 & 29.43 \\
\hline $7:$ & 239 & 247 & 352 & 29.14 & 82 & 91 & 98 & 18.56 \\
\hline 8 & 260 & 436 & 443 & 36.24 & 90 & 95 & 102 & 15.11 \\
\hline 9 & 302 & 359 & 381 & 25.89 & 74 & 84 & 87 & 8.04 \\
\hline A & 63 & 95 & 186 & 22.36 & 39 & 48 & 53 & 21.82 \\
\hline B & 61 & 74 & 99 & 12.11 & 44 & 60 & 66 & 27.11 \\
\hline
\end{tabular}

It is important to note that both $\mathrm{Mo}$ and $\mathrm{Ni}$ contained in the cell-free supernatants that were released by the pre-growth prior to challenging the supernatant with catalyst have been accounted for (subtracted) so that the values shown in the columns in Table 26 represent additional metals release. The results suggest that the cell-free supernatant contains a factor, (a metal releasing factor) MRF, that biosolubilizes $\mathrm{Ni}$ and especially Mo within a very short time frame (24 hours) as evidenced by comparing samples 1-9 to control samples. Several attempts were made to characterize/identify this factor.

\section{Test 28}

Test 28 was a simple straightforward test designed to determine if the mixed heterotrophic denitrifying cultures we were using rbutinely relied on the reduced sulfur present in the catalyst matrix as a nutritional sulfur source. Good growth occurred in citrate $\mathrm{Bm}$ medium if the catalyst was present whereas very poor growth occurred in citrate Bm medium in the absence of catalyst; however good growth cauld later be induced in this later condition by the addition of thiosulfate alone suggesting that the cultures were relying upon the catalyst as a source of nutritional sulfur.

\section{Test 29}

Test 29 was a repeat of test 27 using crushed Shell 324 catalyst and again cellfree supernatant released all of the biosolubilized metals within 24 hours. Sample 1 was crushed catalyst and sample 2 employed whole catalyst (see Table 27). 
Table 27

Effect of Supernatant on Crushed Versus Whole Catalyst

\begin{tabular}{|c|c|c|c|c|c|c|}
\hline \multirow[b]{2}{*}{ Sample } & \multicolumn{2}{|c|}{ ppm Mo } & \multirow[b]{2}{*}{ Day 3} & \multicolumn{3}{|c|}{ ppm Ni } \\
\hline & Day 1 & $\overline{\text { Day } 2}$ & & Day 1 & Day 2 & Day 3 \\
\hline 1 & 738 & 589 & 589 & 194 & 192 & 200 \\
\hline 2 & 561 & 430 & 453 & 143 & 142 & 142 \\
\hline
\end{tabular}

\section{Test 30}

Test 30 tested the idea of pretreating the catalyst for 3 days with 1 molar nitric acid prior to biosolubilization by microbial growth. It was expected that the acid treatment would chemically leach a considerable amount of $\mathrm{Ni}$ and might alter the Mo oxidation state of the Mo remaining in the catalyst matrix leading to better biosolubilization. After three days of nitric acid treatment about $75 \%$ of the $\mathrm{Ni}$ and $25 \%$ of the Mo was removed from the catalyst matrix whereas much lower levels were removed in water controls (data not shown). However, after pre-treatment and 8 days of microbial growth up to $90 \%$ of the Ni and $100 \%$ of the Mo had been solubilized (see Table 28 below).

Table 28

Effect of Nitric Acid Pre-Treatment

\begin{tabular}{|c|l|c|c|}
\hline Sample & Condition $^{\mathrm{a}}$ & \% Release Mo & \% Release Ni \\
\hline 1 & $\mathrm{H} 2 \mathrm{O}$ & 47.78 & 34.46 \\
\hline 2 & $\mathrm{H} 2 \mathrm{O}+$ Azide & 25.21 & 37.85 \\
\hline 3 & Acid & 98.84 & 90.51 \\
\hline 4 & Acid + Thiosulfate & 118.16 & 83.91 \\
\hline
\end{tabular}

a Catalyst was either soaked in water or $1 \mathrm{M}$ nitric acid for three days and the acid or water poured off and replaced with citrate $\mathrm{Bm}$ medium and inoculated with mixed denitrifiers and incubated for 8 days.

\section{Test 31}

Since nitrite is transiently produced by denitrifying bacteria respiring with nitrate, it was thought that nitrite could be the metals releasing factor (MRF) discussed above. A straight chemical test comparing nitrate to nitrite showed that nitrite is not the MRF discussed above (data not shown). 


\section{Test 32}

Test 32 was a straight chemical test designed to determine if various levels of the sodium ion had different effects upon Mo and Ni release. High levels of the sodium ion appear to retard $\mathrm{Ni}$ release, but had little effect upon Mo release (data not shown)

\section{Test 33}

Test 33 was a repeat of Test 27, the cell-free supernatant experiment, except it involved only two conditions. One condition tested supernatant along with added nitrite $(1 \%)$, while the second condition tested supernatant alone (sample 2). Some differences can be noted in this experiment. See Table 29 below for results.

Table 29

Effect of Supernatant Plus Added Nitrite

\begin{tabular}{|c|c|c|c|c|c|c|c|c|}
\hline & \multicolumn{3}{|c|}{ ppm Mo } & \multicolumn{3}{c|}{ ppm Ni } & \% Mo Release & \% Ni Release \\
\hline Sample & Day 1 & Day 2 & Day 3 & Day 1 & Day 2 & Day 3 & Day 3 & Day 3 \\
\hline 1 & 517 & 742 & 784 & 125 & 156 & 167 & 50.28 & 28.08 \\
\hline 2 & 517 & 698 & 687 & 66 & 83 & 151 & 39.4 & 19.08 \\
\hline
\end{tabular}

Test 34

This test was performed to determine if an alternative solvent besides THF could be used to remove coal liquids and not interfere with microbial bio-leaching of the Mo and Ni from spent Shell 324 coal liquefaction catalyst. The alternative solvent used was unleaded gasoline. Even though the gasoline removed coal liquids well, and the resulting catalyst was allowed to air dry, enough residual gasoline remained to inhibit subsequent microbial bioleaching (see Table 30 ).

Table 30

Effect of gasoline pretreatment

\begin{tabular}{|c|c|c|c|}
\hline Sample & Condition & \% Release Mo & $\%$ Release Ni \\
\hline 1 & THF Washed & 43.70 & 40.04 \\
\hline 2 & gasoline washed & 23.08 & 11.71 \\
\hline
\end{tabular}

It is not known why metals release from gasoline washed catalyst was poorer than THF washed catalyst, but an explanation could be that the culture used had acclimated to residual THF through routine subculturing. In this regard, cultures will now also be routinely maintained on gasoline washed catalyst in order to obtain strain tolerance toward gasoline washed Shell 324. 
Test 35

Test 35 was a repeat of test 30 wherein catalyst was further pretreated with $1 \mathrm{M}$ nitric acid and results similar to those shown in table 28 were obtained.

Test 36

Test 36 was essentially a repeat of the cell-free supernatant experiments done earlier (see above) except that in this experiment the supernatant had been concentrated through freeze-drying or lyophilization. The lyophilization had not been taken to completion though, so the supernatant employed in this experiment was about one half the original starting volume; therefore it was about $2 X$ concentrated. Interestingly, (see below Table 31), the concentrated, cell-free supernatant released the majority of the Mo in seven days and about twice as much Mo was released as had been seen in previous experiments (see Table 19, above). The concentrated cell-free supernatant clearly released more Mo than the positive growth control.

Table 31

Release of Metals by Concentrated Supernatant

\begin{tabular}{|c|c|c|c|}
\hline Sample & Condition & \% Mo Release & \% Ni Release \\
\hline 1 & growth & 21.66 & 34.21 \\
\hline 2 & supernatant & 70.76 & 37.02 \\
\hline
\end{tabular}

Test 37

Test 37 was performed to determine if culture inoculum age affects metals release and the test also compared metals release among 5 different enrichment cultures we routinely carry. The test involved ten bottles, 5 of which were inoculated from 5 day old cultures versus 5 bottles which were inoculated from viable one month old cultures. The results (see Table 32 below) show not only that age of inoculum is an important factor in metals release, but also that there exists a quite large variation in the amount of metals released by the different enrichment cultures. 
Table 32

\begin{tabular}{|c|c|c|c|}
\hline Sample & Condition $^{\mathrm{a}}$ & \% Mo Release & \% Ni Release \\
\hline 1 & 5 day & 27.59 & 29.81 \\
\hline 2 & 5 day & 32.43 & 34.96 \\
\hline 3 & 5 day & 49.97 & 45.79 \\
\hline 4 & 5 day & 37.19 & 38.58 \\
\hline 5 & 5 day & 39.46 & 45.21 \\
\hline 6 & month & 50.76 & 45.88 \\
\hline $7^{\mathrm{b}}$ & month & 60.08 & 45.54 \\
\hline $8^{\mathrm{b}}$ & month & 53.09 & 49.69 \\
\hline 9 & month & 45.21 & 45.33 \\
\hline $1^{\mathrm{b}}$ & month & 58.54 & 52.04 \\
\hline
\end{tabular}

a Samples 1-5 refer to enrichment cultures maintained and named 1-5, samples 6-10 refer to these same enrichment cultures respectively but had been inoculated three weeks earlier. Metals release after 6 days growth for all samples.

b These samples showed $100 \%$ Mo release by day 12

\section{Test 38}

Test 38 was a repeat of experiments conducted in the past and it reconfirmed the findings that cell-free supernatant releases metals quickly and more efficiently than culture transfer and or fresh medium rejuvenation (data not shown).

\section{Test 39}

Test 39 was repeat experiment of earlier findings that crushed catalyst released metals faster than whole catalyst and that crushed catalyst generally released a greater quantity of metals. Earlier findings were reconfirmed (data not shown).

\section{Test 40}

Test 40 tested for metals release and compared culture turbidity (growth) so that growth, metals release, and release from different media/catalyst ratios could be compared and contrasted. All samples contained $100 \mathrm{ml}$ of medium, but had different levels of catalyst. See Table 33 below for results. 
Table 33

Effect of Medium/Catalyst Ratios

\begin{tabular}{|c|c|c|c|}
\hline Sample & Condition $^{\mathbf{a}}$ & \% Mo Release & Turbidity \\
\hline 1 & 10.00 & 34.77 & 0.112 \\
\hline 2 & 5.00 & 38.79 & 0.336 \\
\hline 3 & 2.50 & 38.24 & 0.284 \\
\hline 4 & 1.00 & 57.83 & 0.419 \\
\hline 5 & 0.10 & 78.44 & 0.412 \\
\hline 6 & 0.01 & 76.00 & 0.568 \\
\hline 7 & 0.001 & 40.00 & 0.362 \\
\hline 8 & 0.00 & 0.00 & 0.536 \\
\hline
\end{tabular}

a Refers to grams of catalyst contained within the sample bottle, all bottles contained $100 \mathrm{ml}$ Citrate $\mathrm{Bm}$ medium

As can be seen from the data in Table 33, there appears to be an optimum medium/catalyst ratio wherein the greatest percentage Mo release occurs. This ratio is bracketed by catalyst to medium ratios of $1: 100$ to $1 ; 10,000$. It can also be seen that density of growth (turbidity) is also affected by the level of catalyst present. The levels of Ni release did not correlate with any pattern (data not shown).

\section{Test 41}

Test 41 involved setting up sand pack columns interspersed with Shell 324 and running Citrate $\mathrm{Bm}$ medium through the columns on a continuous basis. An attempt was made to optimize this continuous bio-leaching system, but it appeared that about $50 \%$ of the Mo bio-solubilized within the first 24 hours of inoculation and dropped rapidly after that.

\section{Test 42}

Test 42 was a quick test to determine if a newly obtained thermophilic denitrifier (pure culture) could bio-solubilize Mo and Ni from spent catalyst. /The pure culture was Thermothrix thioparus. It was unable to bio-leach any metals.

\section{Test 43}

Test 43 was a retest of the idea that non-pretreated (unwashed with THF) might be used and successfully bio-leached. It was reconfirmed that not using the pretreatment greatly hinders metals release. See Table 34 below. 
Table 34

\begin{tabular}{|c|c|c|c|}
\hline Sample & Condition & \% Mo Release & \% Ni Release \\
\hline 1 & washed & 39.90 & 62.81 \\
\hline 2 & " + Azide & 66.04 & 34.46 \\
\hline 3 & unwashed & 12.25 & 13.71 \\
\hline 4 & "' + AZIDE & 11.79 & 12.71 \\
\hline
\end{tabular}

It is now presumed from experiments performed that the poor metals release from unwashed catalyst is probably not due to any toxic factor in the unwashed catalyst that led to poor growth and consequently low levels of metals release. This assumption was made because good growth can be achieved in the presence of unwashed catalyst as long as some washed catalyst is also included in the growth medium.

\section{Test 44}

Test 44 was a repeat experiment to again show the difference in Mo release from spent coal liquefaction catalyst using cultures of heterotrophic denitrifiers grown under microaerophilic versus strictly anaerobic conditions, and using washed versus unwashed catalyst. Table 35 (below) shows the results of this experiment which measured Mo release after a nine day incubation period. The microaerophilic incubation released the most $M o$ and it was seen again that unwashed catalyst had low levels of Mo release compared to THF pre-treated catalyst incubations.

Table 35

Microaerophilic Versus Anaerobic Metals Release

\begin{tabular}{|c|c|c|c|}
\hline Sample & Condition & \% Ni Release & \% Mo Release \\
\hline 1 & $\mathrm{MA}^{\mathrm{a}}$ washed & 36.67 & 52.82 \\
\hline 2 & MA unwashed & 10.79 & 11.53 \\
\hline$\overline{3}$ & $\mathrm{~A}^{\mathrm{b}}$ washed & 31.44 & 32.54 \\
\hline$\overline{4}$ & A unwashed & 9.10 & 7.34 \\
\hline
\end{tabular}

a-microaerophilic b-anaerobic

\section{Test 45}

Test 45 was a repeat experiment of a test done last quarter in which cell-free supernatant, which is thought to contain a metals releasing factor (MRF), is used to effect metals solubilization. However, in this particular test, THF washed catalyst 


\section{Effect of Cell-Free Supernatant Age on Metals Release}

\section{TEST 45}

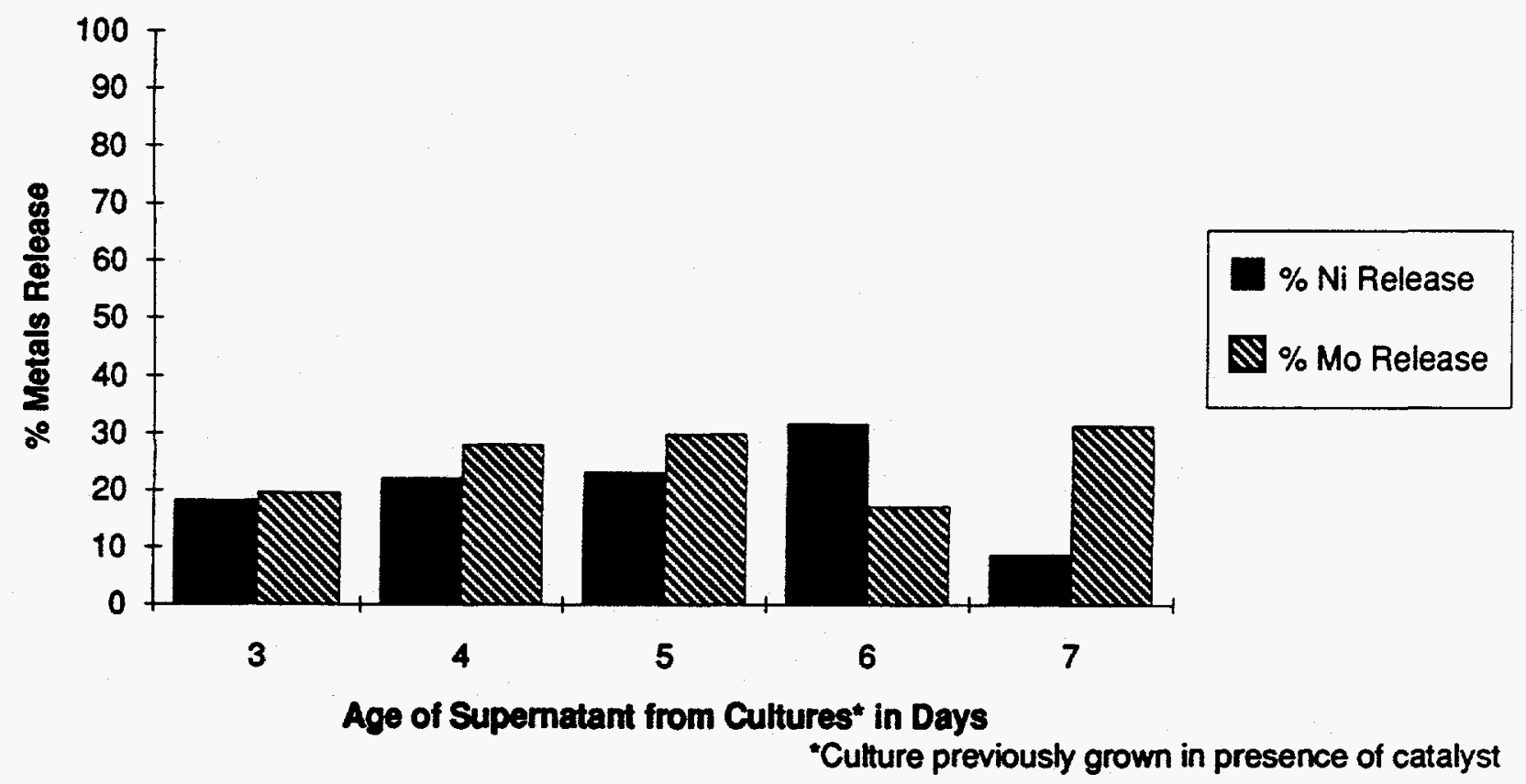


was challenged with cell-free supernatant derived from cultures that had been grown $3,4,5,6$, and 7 days in the presence of catalyst. The results reported below (Table 36) reflect the average of duplicate incubations and metals release after 24 hours.

Table 36

Effect of Cell-Free Supernatant Age on Metals Release

\begin{tabular}{|c|c|c|c|}
\hline Sample & Supernatant Age & \%Ni Release & \%Mo Release \\
\hline 1 & 3 days & 18.33 & 19.56 \\
\hline 2 & 4 days & 22.08 & 28.07 \\
\hline 3 & 5 days & 23.13 & 29.88 \\
\hline 4 & 6 days & 31.67 & 17.19 \\
\hline 5 & 7 days & 8.75 & 31.38 \\
\hline
\end{tabular}

It can be seen from the data presented in Table 36 that there is an difference in metals release depending upon the age of the cell-free supernatant used to biosolubilize the catalyst in a 24 hour period. It is not known why so little $\mathrm{Ni}$ was solubilized using the 7 day old supernatant, but that this could possibly arise from redeposition of $\mathrm{Ni}$ that was discovered in earlier research where $\mathrm{Ni}$ was initially solubilized by growing cultures, only to be redeposited into the catalyst matrix.

\section{Test 46}

Test 46 was an experiment designed to determine the optimum catalyst to medium ratio that would yield the greatest percentage metals release. It appears that from the data presented below (Table 37), that at around a ratio of 5 grams of catalyst to $100 \mathrm{ml}$ of medium there is a drop in percentage efficiency metals removal, although greater ppm metals were solubilized in incubations that contained a greater mass of catalyst. All samples contained $100 \mathrm{ml}$ of medium, but different amounts of catalyst. The results presented are values obtained after a 5 day incubation period.

Table 37

Metals Release Dependant Upon Catalyst Load

\begin{tabular}{|c|c|c|c|c|c|}
\hline Sample & Condition & ppmNi & $\%$ Ni & PpmMo & $\%$ Mo \\
\hline 1 & $1.00 \mathrm{~g}$ & 36 & 14.85 & 223 & 26.91 \\
\hline 2 & $2.50 \mathrm{~g}$ & 88 & 14.57 & 518 & 24.98 \\
\hline 3 & $5.00 \mathrm{~g}$ & 141 & 11.60 & 677 & 16.45 \\
\hline 4 & $7.50 \mathrm{~g}$ & 182 & 9.96 & 1015 & 16.42 \\
\hline 5 & $10.00 \mathrm{~g}$ & 200 & 8.24 & 1308 & 15.88 \\
\hline
\end{tabular}


It should also be noted that turbidity measurements taken on day 5 indicated a range of turbidities starting at 1.067 for the sample containing the least amount of catalyst, and the tubidity measurements declined in value (less growth) as the weight of the catalyst added was increased to a low of 0.585 for sample 5 (all data not shown).

\section{Test 47}

Test 47 determined the effect of 3 treatments upon either unwashed or THF washed catalyst samples. Samples 1-3 were THF washed catalyst, and samples 4-6 were replicates of 1-3 except unwashed catalyst was used. Sample 1 was treated with uninoculated $\mathrm{Bm}$ medium for 24 hours at which time a sample was taken for metals removal measurement. Then new medium was added and it was inoculated and incubated for 12 days. Sample 2 was treated similarly to sample 1 except the 24 hr treatment prior to medium addition and inoculum was $3 \%$ hydrogen peroxide. Sample 3 was treated similarly to sample 1 except the 24 treatment prior to medium addition and inoculum was a very dilute solution of nitric acid the $\mathrm{pH}$ of which measured 2. Samples 4-6 were treated as samples 1,2, and 3, but used non solvent washed catalyst. Total \% metals removal, after pretreatment and a 12 day incubation period is reported below in Table 38.

Table 38

Pre-Treatment of Washed and Unwashed Catalyst

\begin{tabular}{|c|c|c|c|}
\hline Sample & Condition & \%Ni Released & \%Mo Released \\
\hline 1 & $\mathrm{BM}$ & 56.90 & 66.41 \\
\hline 2 & $\mathrm{H} 2 \mathrm{O} 2$ & 82.17 & 121.89 \\
\hline 3 & Nitric & 56.81 & 73.84 \\
\hline 4 & $\mathrm{BM}$ & 9.06 & 14.84 \\
\hline 5 & $\mathrm{H} 2 \mathrm{O} 2$ & 28.73 & 45.06 \\
\hline 6 & Nitric & 12.54 & 24.85 \\
\hline
\end{tabular}

It is evident from the results obtained in test 47 that various pre-treatment regimens can greatly influence $\mathrm{Ni}$ and $\mathrm{Mo}$ release when the pre-treated catalyst is later bio-leached. Also, it was found that the different pre-treatment regimens release different levels of metals prior to subjecting the catalyst to bio-leaching, with $3 \% \mathrm{H}_{2} \mathrm{O}_{2}$ pre-treatment leading to the greatest pre-release (data not shown).

\section{Test 48}

Test 48 was a simple repeat experiment to reconfirm that the medium, citrate $\mathrm{Bm}$ solubilized metals better than deionized water. Both samples were not inoculated and no growth occurred in either sample. Metals release was about twice as great in the citrate $\mathrm{Bm}$ medium which reconfirmed earlier findings (data not shown). 


\section{Test 49}

Test 49 examined metals solubilization using different concentrations of hydrogen peroxide using THF washed, and unwashed catalyst and the effect of added iron in this system. Iron, in the form of ferrous sulfate was added to some samples as it was thought iron might generate free radicals in the presence of peroxide. However, the addition of iron had only one marked effect and this was in the case of unwashed catalyst. All sample conditions contained 1 gram of catalyst with metals release measured after 48 hours. See Table 39 below.

Key to Sample Condition for Table 39:

Sample \#

$1 \mathrm{THF}$ washed in $100 \mathrm{ml} 3 \% \mathrm{H}_{2} \mathrm{O}_{2}$

2 THF washed in $100 \mathrm{ml} 3 \% \mathrm{H}_{2} \mathrm{O}_{2}$ with $0.05 \mathrm{~g}$ Ferrous Sulfate

3 Unwashed in $100 \mathrm{ml} 3 \% \mathrm{H}_{2} \mathrm{O}_{2}$

4 Unwashed in $100 \mathrm{ml} 3 \% \mathrm{H}_{2} \mathrm{O}_{2}$ with $0.05 \mathrm{~g}$ Ferrous Sulfate

5 THF washed in $100 \mathrm{ml} 10 \% \mathrm{H}_{2} \mathrm{O}_{2}$

6 Unwashed in $100 \mathrm{ml} 10 \% \mathrm{H}_{2} \mathrm{O}_{2}$

7 THF washed in $100 \mathrm{ml} \mathrm{dH} 2 \mathrm{O}$

8 Unwashed in $100 \mathrm{ml} \mathrm{dH} 2 \mathrm{O}$

Table 39

Effect of $\mathrm{H}_{2} \mathrm{O}_{2}$ and Iron On Metals Release

\begin{tabular}{|c|c|c|}
\hline Sample & \%Ni Release & \%Mo Release \\
\hline 1 & 74.38 & 98.15 \\
\hline 2 & 76.46 & 98.38 \\
\hline 3 & 38.98 & 49.05 \\
\hline 4 & 10.58 & 2.91 \\
\hline 5 & 74.38 & 100.96 \\
\hline 6 & 59.88 & 71.79 \\
\hline 7 & 26.13 & 16.28 \\
\hline 8 & 2.00 & 0.36 \\
\hline
\end{tabular}

At the present time, it is unknown why the inclusion of ferrous iron along with $\mathrm{H}_{2} \mathrm{O}_{2}$ to treat unwashed catalyst so greatly inhibited metals solubilization (sample \#4). 


\section{Effect of H2O2 and Ferrous Sulfate Extraction on Metals Release TEST 49}

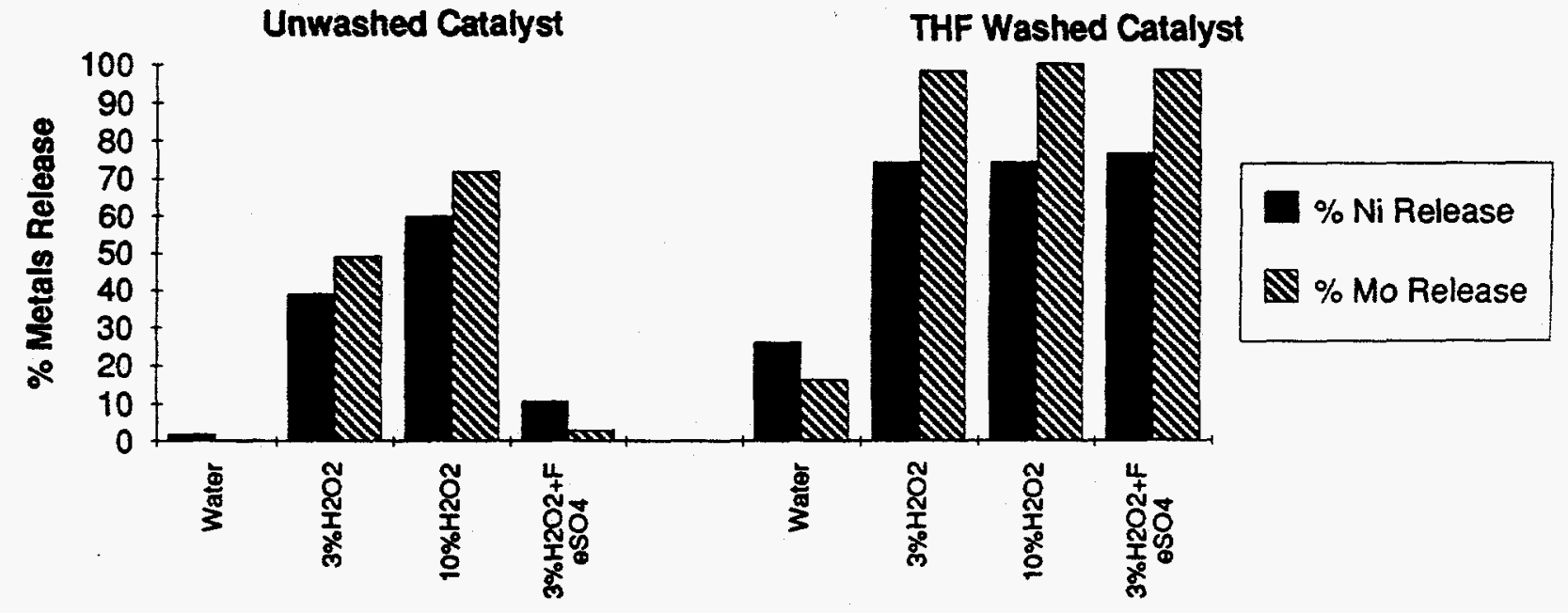

Extractant with 48 hour contact time 
Test 50

Test 50 was a re-examination of gasoline an alternative to THF as a solvent for removing coal liquids prior to bio-solubilization of the catalyst metals. Regular unleaded gasoline had been tested previously, but subsequent metals biosolubilization was very limited. This test differed in that the catalyst was challenged with a mixed, heterotrophic, denitrifying culture that had been adapted to gasoline washed catalyst (i.e. eventually the culture grew well in the presence of gasoline washed catalyst). Even though the culture grew quite well in this test, metals solubilization after 2 weeks did not exceed $10 \%$ which was similar to the prior test (data not shown).

\section{Test 51}

Test 51 was a re-examination of $\mathrm{H}_{2} \mathrm{O}_{2}$ as a metals releasing agent that was used on both THF washed and unwashed coal liquefaction catalyst. Results obtained were similar to that reported in Test 49 . Virtually all the Mo and about $75 \%$ of the $\mathrm{Ni}$ were removed from the catalyst matrix within 24 hours, but only about $50 \%$ of the Mo and Ni were removed from the unwashed catalyst after a period of 4 days.

\section{$\underline{\text { Test } 52}$}

Test 52 was performed using unwashed catalyst and was carried out to determine if the oxidizing nature of $\mathrm{H}_{2} \mathrm{O}_{2}$ is an important part of its metals releasing activity. Tests were performed with $3 \% \mathrm{H}_{2} \mathrm{O}_{2}$ (one gram of catalyst) and either 100 $\mathrm{ml}$ of $3 \% \mathrm{H}_{2} \mathrm{O}_{2}$ or $97 \mathrm{ml}$ of $3 \% \mathrm{H}_{2} \mathrm{O}_{2}$ along with $3 \mathrm{ml}$ of $37 \%$ formaldehyde which can act as a reducing agent. Whereas about $50 \%$ of the Mo was released in 2 days in the test with only $\mathrm{H}_{2} \mathrm{O}_{2}$ present, only about $25 \%$ of the Mo was released in the test bottle that contained $3 \mathrm{ml}$ of the $37 \%$ formaldehyde.

\section{Test 53}

Test 53 was performed using $3 \% \mathrm{H}_{2} \mathrm{O}_{2}$ and varying amounts of THF washed catalyst to determine the greatest mass of catalyst that can be effectively leached in a fixed period of time. The results shown below (Table 40) suggest that metals solubilization becomes less efficient when the ratio of 5 grams catalyst to $100 \mathrm{ml}$ of $\mathrm{H}_{2} \mathrm{O}_{2}$ is exceeded.

Table 40

Effect Catalyst $\mathrm{H}_{2} \mathrm{O}_{2}$ Ratio $^{\text {a }}$

\begin{tabular}{|c|c|c|c|}
\hline Sample & Catalyst Weight & \%Ni Release & \%Mo Release \\
\hline 1 & 10.0 & $65.35 \cdot$ & 54.23 \\
\hline
\end{tabular}




\section{Effect of Catalyst Concentration on Metals Release TEST 53}

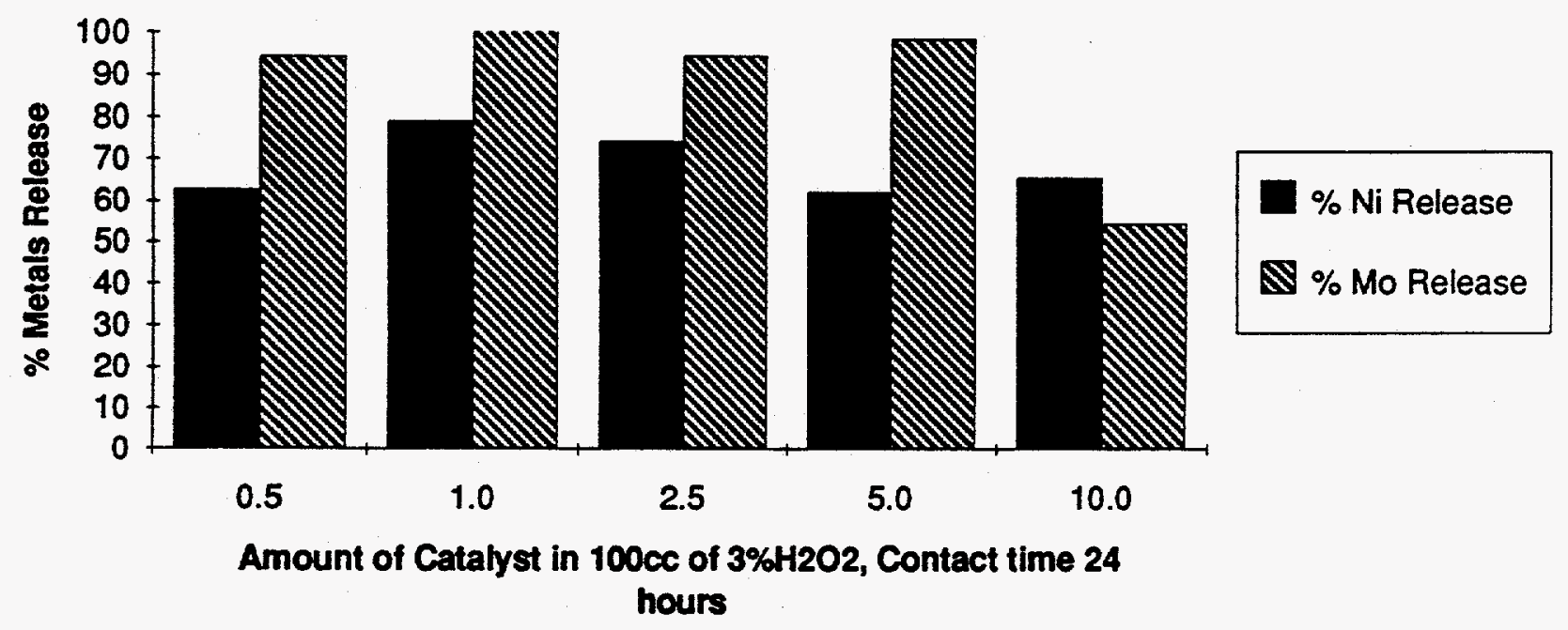




\begin{tabular}{|c|c|c|c|}
\hline 2 & 5.0 & 62.06 & 98.42 \\
\hline 3 & 2.5 & 74.14 & 94.50 \\
\hline 4 & 1.0 & 79.02 & 106.36 \\
\hline 5 & 0.5 & 62.67 & 94.40 \\
\hline
\end{tabular}

a-metals release measured after 24 hours

\section{Test 54}

Test 54 was a re-examination of the effect of catalyst size as it pertains to metals release similar to tests conducted earlier, but, in this case, using $3 \% \mathrm{H}_{2} \mathrm{O}_{2}$ instead of microbial cultures. Again it was found, as in the previous tests, that decreasing catalyst particle size greatly facilitated metals release, but that this difference was only noticeable when analysis of samples were time compressed; i.e. differences could be noted 1 hour after exposure of the various catalyst sized particles to $3 \% \mathrm{H}_{2} \mathrm{O}_{2}$ treatment, but differences were much less noticeable when sample analysis was performed 8 hours after initiation of the experiment. See Table 41 below for results obtained after 1 and 8 hour treatments.

Table 41

\section{Effect of Particle Size During $\mathrm{H}_{2} \mathrm{O}_{2}$ Treatmenta}

\begin{tabular}{|c|c|c|c|}
\hline Sample & Condition & \%Ni Release & \%Mo Release \\
\hline 1 & $>30$ mesh & 37.08 & 39.50 \\
\hline 2 & $<30$ mesh & 53.75 & 64.00 \\
\hline 3 & $<60$ mesh & 55.83 & 60.75 \\
\hline 4 & not ground & 20.83 & 19.25 \\
\hline 5 & $>30$ mesh & 71.90 & 90.18 \\
\hline 6 & $<30$ mesh & 70.85 & 91.40 \\
\hline 7 & $<60$ mesh & 69.50 & 89.66 \\
\hline 8 & not ground & 69.52 & 70.55 \\
\hline
\end{tabular}

a-first 4 samples, metals release at 1 hour; samples $5-8$ same as 1-4, but release measured at 8 hours

Test 55

Test 55 was designed to test different solvents for removing coal liquids prior to subsequent $\mathrm{H}_{2} \mathrm{O}_{2}$ leaching, analogous to previous tests using bio-leaching. The solvents tested were THF, xylene, acetone, and methanol. As in previous tests, THF was found to be the superior solvent for pre-treatment prior to leaching (See Table 42 below). 
Effect of Particle Size on 3\% $\mathrm{H} 2 \mathrm{O} 2$ and Metals Release TEST 54

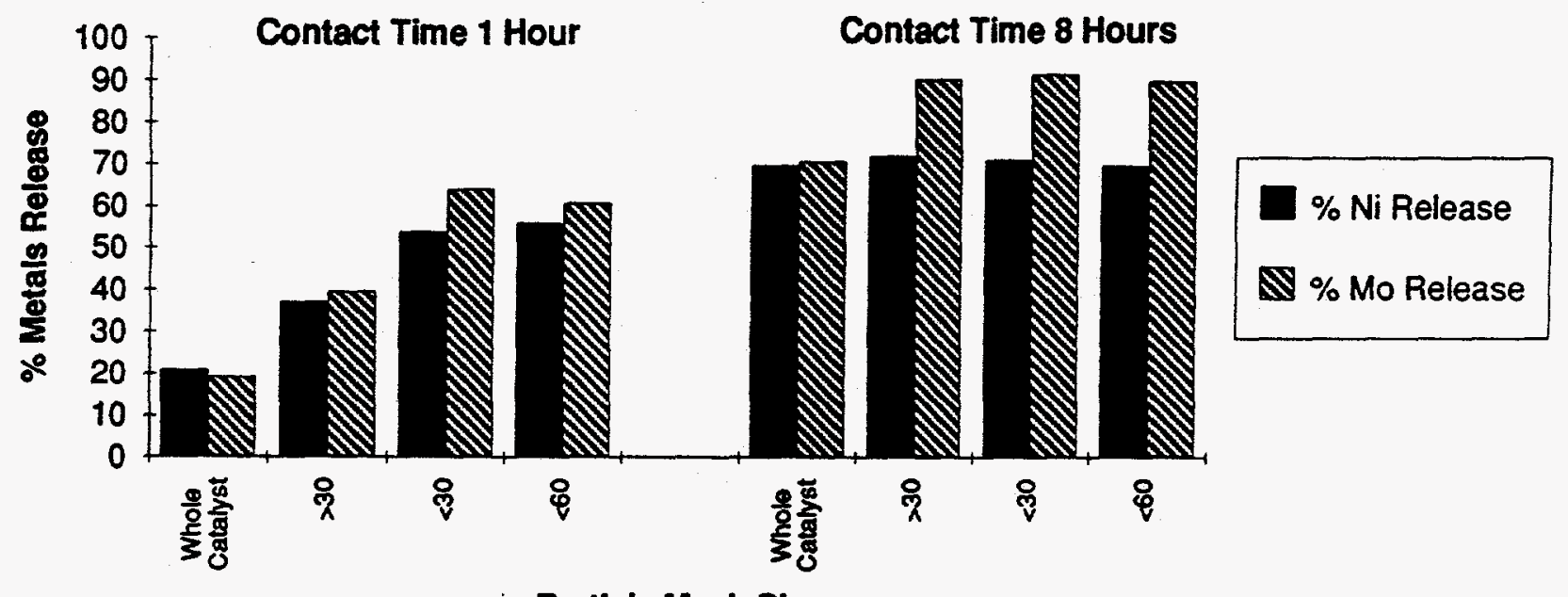

Particle Mesh Size 


\section{Effect of Solvent Washes on 3\% H2O2 Metals Release TEST 55}

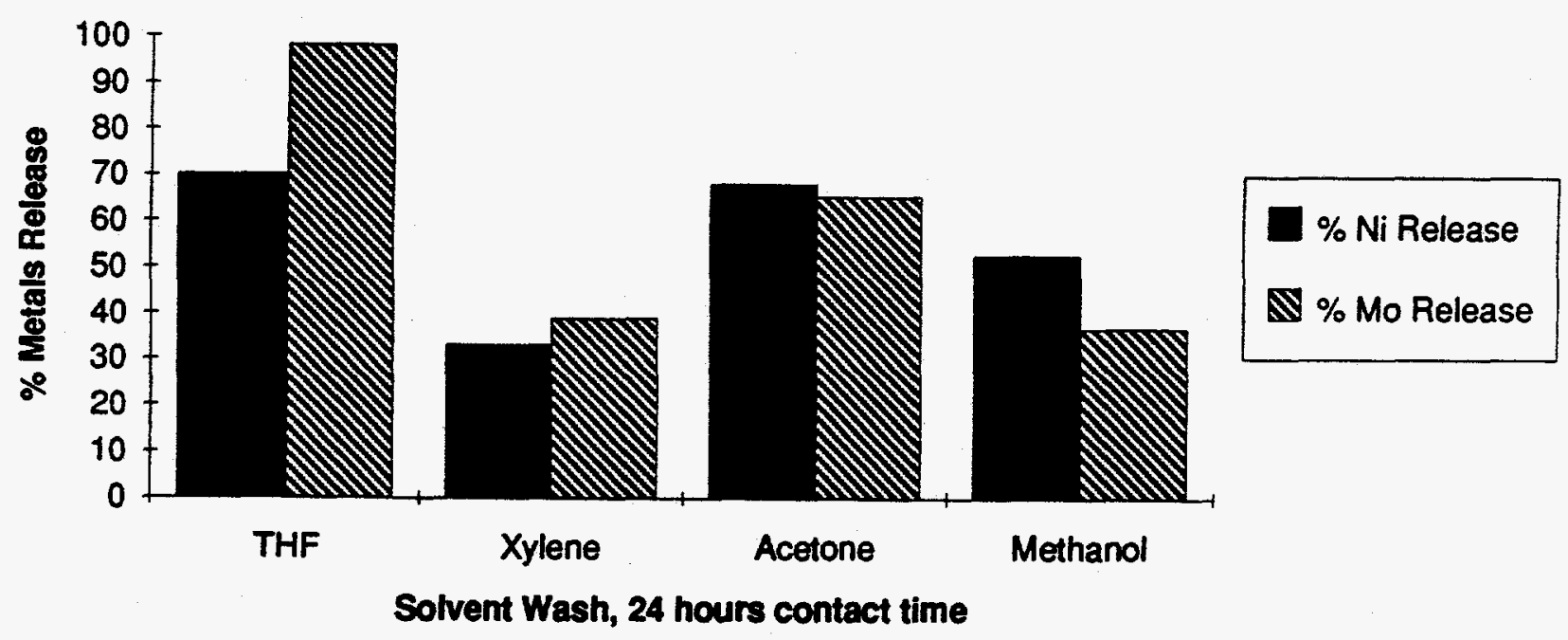


Table 42

Effect of Different Solvents in $\mathrm{H}_{2} \mathrm{O}_{2}$ Leaching ${ }^{\mathrm{a}}$

\begin{tabular}{|c|c|c|c|}
\hline Sample & Condition & \%Ni Release & \%Mo Release \\
\hline 1 & THF & 70.15 & 98.20 \\
\hline 2 & Xylene & 32.92 & 38.75 \\
\hline 3 & Acetone & 67.92 & 65.13 \\
\hline 4 & Methanol & 52.50 & 36.60 \\
\hline
\end{tabular}

a-metals release measured after 24 hours contact time

It is highly possible that these alternative solvents might yield results in the $\mathrm{H}_{2} \mathrm{O}_{2}$ leaching system if longer periods of pre-solvent treatment had been employed. The catalyst samples in this test were only washed for 24 hours prior to treatment and a longer washing period or catalyst washing using a soxhlet apparatus might have yielded better results.

\section{Test 56}

Similar, independent, in-house research using both $3 \%$ and $30 \% \mathrm{H}_{2} \mathrm{O}_{2}$ diluted to $3 \%$ showed differences in leaching ability towards certain sulfide ores and catalysts other than Shell 324. It was thought that the use of 2 different $\mathrm{H}_{2} \mathrm{O}_{2}$ stabilizers, phosphoric acid and acetanilide might account for these differences or that, upon dilution of the $30 \% \mathrm{H}_{2} \mathrm{O}_{2}$, additional stabilizer might need to be added. However, tests using either $3 \% \mathrm{H}_{2} \mathrm{O}_{2}$ or $30 \% \mathrm{H}_{2} \mathrm{O}_{2}$ diluted to a $3 \%$ concentration showed no differences using Shell 324 as the test catalyst (data not shown).

\section{Test 57}

Test 57 was designed to determine the number of times an aliquot of $3 \% \mathrm{H}_{2} \mathrm{O}_{2}$ could be re-used to leach a new 1 gram quantity of THF washed catalyst. Obtaining this information was deemed important since the economics of the $\mathrm{H}_{2} \mathrm{O}_{2}$ leaching process would be increased if the $\mathrm{H}_{2} \mathrm{O}_{2}$ could be re-used or re-cycled several times. The data shown below indicate that $\mathrm{H}_{2} \mathrm{O}_{2}$ can be re-used several times (see Table 43). In the experimental data shown below, sample 1 represents 1 gram of THF washed Shell 324 contacted with $100 \mathrm{ml}$ of $3 \% \mathrm{H}_{2} \mathrm{O}_{2}$ for a 24 hour period. After the 24 hour contact period, a $5 \mathrm{ml}$ aliquot was removed for analysis of the $\mathrm{Ni}$ and Mo leached into solution. The remaining $95 \mathrm{ml}$ of this leachate was then challenged with a new 1 gram sample of THF washed catalyst and this was sample 2 and was likewise analyzed after 24 hours. This process was repeated for samples 3,4,5 and 6 except that sample 5 was analyzed after 3 days contact time and sample 6 was analyzed after 8 days contact time. It should be noted that each successive test sample had $5 \mathrm{ml}$ less $\mathrm{H}_{2} \mathrm{O}_{2}$ because a $5 \mathrm{ml}$ aliquot was removed at each time point before further re-use of the remaining $\mathrm{H}_{2} \mathrm{O}_{2}$ solution which contained successively higher levels of leached $\mathrm{Ni}$ and Mo. 
Concentration of Metals Release by Reuse of 3\% H2O2

\section{TEST 57}

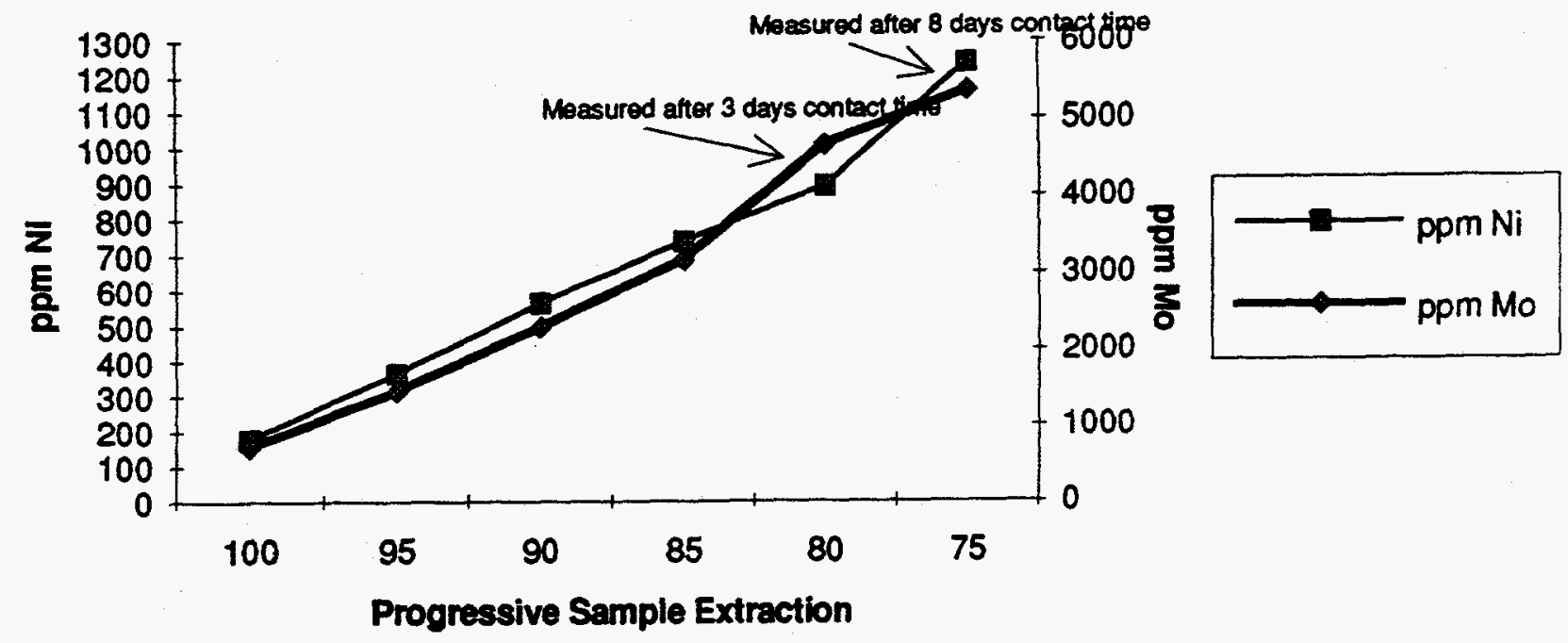


Concentration of Metals Released by Reuse of $3 \% \mathrm{H} 2 \mathrm{O} 2$ Test 57

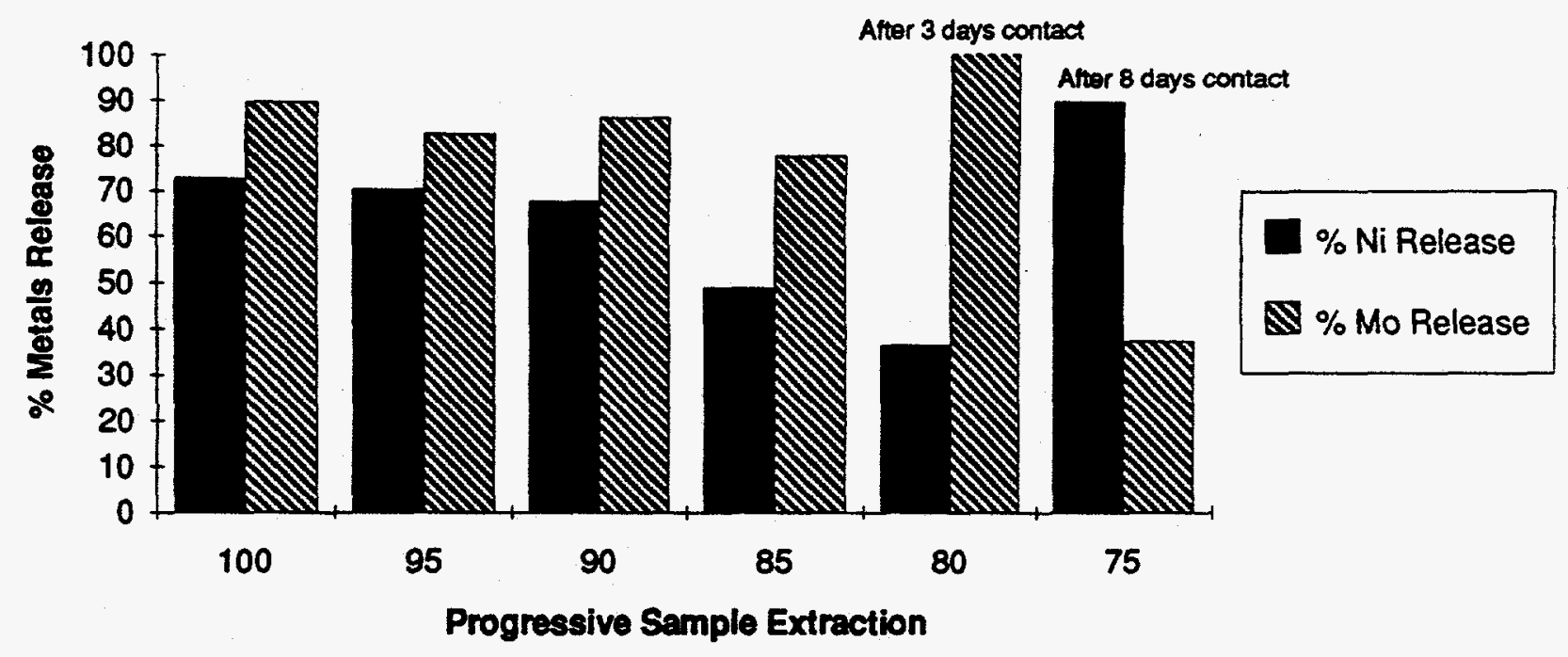


Table 43

Re-Use of $\mathrm{H}_{2} \mathrm{O}_{2}$ Leachate

\begin{tabular}{|c|c|c|c|c|c|}
\hline Sample & Volume & PPMNi & \%NiRel & PPMMo & \%Mo Rel \\
\hline 1 & 100 & 177 & 72.63 & 718 & 89.75 \\
\hline 2 & 95 & 364 & 70.33 & 1451 & 82.56 \\
\hline 3 & 90 & 565 & 67.79 & 2297 & 86.11 \\
\hline 4 & 85 & 736 & 48.79 & 3162 & 77.55 \\
\hline 5 & 80 & 891 & 36.33 & 4649 & $128.94^{\mathrm{a}}$ \\
\hline 6 & 75 & 1237 & 89.56 & 5357 & $37.32^{\mathrm{b}}$ \\
\hline
\end{tabular}

a-measured after 3 days contact time

b-measured after 8 days contact time

Test 58

Test 58 was a retest of the thermophilic enrichment culture (started from inocula obtained from Yellowstone National Park) which, upon initial enrichment, had not shown significant bio-leaching ability. After initial tests showed little bioleaching ability, the enrichment culture was routinely cultivated for several months in the presence of catalyst in an attempt to improve its tolerance of the catalyst and perhaps improve the bio-leaching capacity of the enrichment consortium. No significant improvements in bio-leaching ability were noted for this thermophilic enrichment culture.

\section{General Discussion and Conclusions}

Individual test results and their importance have been separately discussed in each section of the test program. This was done because of the many variables and conditions which have been investigated, each of which is important in effecting or retarding the release of the metals from the catalyst.

An overall examination of these findings show that the release of Mo is dependent upon many parameters, but is dominated by microbial growth in a bioleaching system. Such microbial Mo release is a rapid process usually requiring less than 1 week for $90 \%$ of the releasable Mo to be solubilized. Efforts performed in the research presented here centered on optimizing the parameters that stimulate microbial growth and action. It is suggested that if further research is continued, it should pursue those medium components and incubation conditions which best promote the microbial release of Mo. Another avenue of research (since $\mathrm{Ni}$ is toxic to many microorganisms) should investigate the possibility of promoting $\mathrm{Mo}$ release microbially by first leaching $\mathrm{Ni}$ (using leaching techniques other than chemical chelation) and then subjecting the preleached catalyst to microbial Mo 
release. An example of this would be the highly efficient $\mathrm{H}_{2} \mathrm{O}_{2}$ extraction technology demonstrated for this project. Also, although not demonstrated in this project, the products of microbial growth $\left(\mathrm{H}_{2} \mathrm{O}_{2}\right.$ ?) rather than microbial growth per se may be important in this Mo release system. In this regard, further efforts should be made at determining the role of air (oxygen) in its suggested importance in furthering Mo release. It was found in this research that thermophily conferred no advantage in this bio-leaching technology, but further efforts should be made to study thermophiles obtained from appropriate highly selective habitats such as thermal areas of high metal sulfide content.

While the majority of the research performed for this project centered on the physio-chemical parameters that optimized microbial bio-leaching of metals from spent coal liquefaction catalyst, many other factors were investigated, and in many cases it was found that $100 \%$ of the Mo on spent catalyst could be solubilized. One of the theories generated by these investigations was the idea that not only is microbial growth important in a metals solubilization system, but also it may be that a product of microbial growth can serve as a metals releasing agent. Attempts were made to isolate or characterize a metals releasing agent or metals releasing factor (MRF) and those attempts were largely unsuccessful; however, supernatant, concentrated by lyophilization, revealed a metals releasing ability. The metals releasing factor was never characterized, but a well known by-product of microbial metabolism, $\mathrm{H}_{2} \mathrm{O}_{2}$, was chosen as microbial metabolic by-product that merited further investigation.

Experiments testing the ability of $\mathrm{H}_{2} \mathrm{O}_{2}$ to solubilize metals were surprizingly successful (see above). Not only were $100 \%$ of the Mo and $75 \%$ of theNi leached into solution in typical tests, but also it was found that the action of $\mathrm{H}_{2} \mathrm{O}_{2}$ in its metals leaching ability was quite rapid. $3 \% \mathrm{H}_{2} \mathrm{O}_{2}$ could usually leach about $100 \%$ of the Mo and about $75 \%$ of the $\mathrm{Ni}$ in 24 hours, and whereas bio-solubilization with heterotrophic denitrifying also could also approach this high level of solubilization, the biological process usually required a period of more than a week. Tests revealed that both systems worked best when the liquid to catalyst ratio was near 100 to 1 . The price of the Citrate $\mathrm{Bm}$ medium (retail chemical costs) and the price of $3 \% \mathrm{H}_{2} \mathrm{O}_{2}$ are about equivalent; however, since the $3 \% \mathrm{H}_{2} \mathrm{O}_{2}$ system performs the necessary leaching about 10 times faster, it would be more economically feasible to recycle Mo and $\mathrm{Ni}$ using the $3 \% \mathrm{H}_{2} \mathrm{O}_{2}$ system. This economically superior method is further favored due to the absence of labor that is involved in bio-leaching system where time and labor must be expended to prepare the appropriate medium. 